\title{
Mucin glycoproteins block apoptosis; promote invasion, proliferation, and migration; and cause chemoresistance through diverse pathways in epithelial cancers
}

\author{
Ian S. Reynolds ${ }^{1,2}$ (1) $\cdot$ Michael Fichtner ${ }^{2} \cdot$ Deborah A. McNamara ${ }^{1,3} \cdot$ Elaine W. Kay ${ }^{4,5} \cdot$ Jochen H.M. Prehn $^{2} \cdot$ \\ John P. Burke ${ }^{1}$
}

Published online: 24 January 2019

C Springer Science+Business Media, LLC, part of Springer Nature 2019

\begin{abstract}
Overexpression of mucin glycoproteins has been demonstrated in many epithelial-derived cancers. The significance of this overexpression remains uncertain. The aim of this paper was to define the association of mucin glycoproteins with apoptosis, cell growth, invasion, migration, adhesion, and clonogenicity in vitro as well as tumor growth, tumorigenicity, and metastasis in vivo in epithelial-derived cancers by performing a systematic review of all published data. A systematic review of PubMed, Embase, and the Cochrane Central Register of Controlled Trials was performed to identify all papers that evaluated the association between mucin glycoproteins with apoptosis, cell growth, invasion, migration, adhesion, and clonogenicity in vitro as well as tumor growth, tumorigenicity, and metastasis in vivo in epithelial-derived cancers. PRISMA guidelines were adhered to. Results of individual studies were extracted and pooled together based on the organ in which the cancer was derived from. The initial search revealed 2031 papers, of which 90 were deemed eligible for inclusion in the study. The studies included details on MUC1, MUC2, MUC4, MUC5AC, MUC5B, MUC13, and MUC16. The majority of studies evaluated MUC1. MUC1 overexpression was consistently associated with resistance to apoptosis and resistance to chemotherapy. There was also evidence that overexpression of MUC2, MUC4, MUC5AC, MUC5B, MUC13, and MUC16 conferred resistance to apoptosis in epithelialderived cancers. The overexpression of mucin glycoproteins is associated with resistance to apoptosis in numerous epithelial cancers. They cause resistance through diverse signaling pathways. Targeting the expression of mucin glycoproteins represents a potential therapeutic target in the treatment of epithelial-derived cancers.
\end{abstract}

Keywords Mucin glycoproteins $\cdot$ Epithelial cancer $\cdot$ Chemoresistance $\cdot$ Apoptosis

\section{Introduction}

Programmed cell death (PCD) refers to all types of cell death activated by intracellular death programs. PCD is important in

John P. Burke

johnburke@rcsi.ie

1 Department of Colorectal Surgery, Beaumont Hospital, Dublin 9, Ireland

2 Department of Physiology \& Medical Physics, Royal College of Surgeons in Ireland, 123 St. Stephens Green, Dublin 2, Ireland

3 Department of Surgery, Royal College of Surgeons in Ireland, $123 \mathrm{St}$. Stephens Green, Dublin 2, Ireland

4 Department of Pathology, Beaumont Hospital, Dublin 9, Ireland

5 Department of Pathology, Royal College of Surgeons in Ireland, 123 St. Stephens Green, Dublin 2, Ireland balancing cell death and survival and occurs in normal cells during development and in adulthood. Depending on the types of intracellular signaling pathways activated, PCD may lead to the activation of apoptosis, autophagic cell death, or a programmed form of necrosis termed 'necroptosis' [1]. In cancer cells, a disturbance in the equilibrium of any of these programs may contribute to tumor progression and resistance to therapy $[2,3]$. Apoptosis typically occurs when there is irreparable DNA damage within a cell. The induction of apoptosis can occur via one of two pathways, the extrinsic (death receptor) pathway or the intrinsic (mitochondrial) pathway [4]. The extrinsic pathway is initiated by binding of death ligands such as Fas ligand (Fas-L) or TNF-related apoptosis inducing ligand (TRAIL) to plasma membrane death receptors. In the case of Fas-L, binding to Fas receptors leads to the recruitment of the death domain-containing protein Fas-associated protein with death domain (FADD) and pro-caspase 8 . These then 
aggregate to form the death-inducing signaling complex (DISC). DISC goes on to activate pro-caspase-8 which triggers the activation of pro-caspase-3, an enzyme that is fundamental in the apoptotic process [5]. Apoptosis via the internal pathway is under control of mitochondrial proteins of the BCL-2 family. In this pathway, pro-apoptotic Bcl-2 proteins Bax and Bak permeabilize outer mitochondrial membranes to release cytochrome $\mathrm{C}$ into the cytosol. Cytochrome $\mathrm{C}$ recruits the adaptor protein Apaf-1 and pro-caspase- 9 to generate the apoptosome, which triggers a caspase-9/3 signaling cascade, culminating in apoptosis [6]. Death receptor-induced apoptosis also engages the intrinsic or mitochondrial apoptosis pathway through caspase-8-mediated cleavage of the Bax- and Bak-activating protein Bid. There is evidence that abnormal expression of some of the key regulatory factors in these processes may lead to cancer progression and resistance and cross-resistance of cancer cells to chemo- and radiotherapy.

Mucins (MUC) are high molecular weight O-glycoproteins that are typically expressed at the apical surface of epithelial cells [7-9]. Expression of mucins is tissue specific and these glycoproteins participate in essential functions such as protection, lubrication to epithelial cells, maintenance of epithelial characteristics, cellular adhesion, differentiation, and immunity [10-16]. The expression of mucin glycoproteins has been shown to be altered in many pathological conditions such as inflammatory bowel disease and neoplasia [17-28]. In some of these conditions, mucin overexpression predominates, while in others, downregulation of mucins can be observed. For example, MUC4 has been shown to be overexpressed in pancreatic, breast, and gastric cancer [29-31], while its expression is reduced in prostatic and urothelial cancers $[32$, 33]. It is very plausible that mucin glycoproteins may play a key role in the setting of epithelial neoplasia. We hypothesize that mucin glycoproteins may exert anti-apoptotic effects and hence induce chemoresistance in epithelial malignancies.

The aim of this study was to identify and summarize all the studies to date examining the effects of mucin glycoproteins on apoptosis, cell growth, invasion, migration, adhesion, and clonogenicity in vitro as well as tumor growth, tumorigenicity, and metastasis in vivo in epithelial-derived cancers.

\section{Materials and methods}

\subsection{Literature search and study selection}

This systematic review adhered to the recommendations of the PRISMA (Preferred Reporting Items of Systematic Reviews and Meta-analysis) statement [34]. A systematic search of PubMed, Embase, and the Cochrane Central Register of Controlled Trials was performed for all studies that investigated the role of mucin glycoproteins in apoptosis, cell growth, invasion, migration, adhesion, and clonogenicity in vitro as well as tumor growth, tumorigenicity, and metastasis in vivo in epithelial-derived cancers. The following search terms were used in the search algorithm: (mucin OR mucinous) AND (apoptosis OR necrosis OR cell death) AND (proliferation OR migration OR invasion OR tumorigenicity OR resistance) AND (cancer OR adenocarcinoma). A second search strategy was also used to identify manuscripts detailing the role of mucin glycoproteins in stem cells: (Mucins) AND (cancer stem cells). The latest search was performed on the 10 December 2018. Two authors (I.S.R and J.P.B) independently examined the title and abstract of citations, and the full texts of potentially eligible studies were obtained; disagreements were resolved by discussion or if needed by a third author (D.A.M). The reference lists of all articles that were retrieved were further screened for additional eligible publications.

\subsection{Eligibility criteria}

All studies that investigated the role or association of mucin glycoproteins with apoptosis, cell growth, invasion, migration, adhesion, and clonogenicity in vitro as well as tumor growth, tumorigenicity, and metastasis in vivo in epithelialderived cancers were eligible for inclusion. In order to be eligible, studies had to be performed on cell lines or animal models. Any studies using patient samples were not included. Papers pertaining to ovarian cancer were excluded. There were no language restrictions.

\subsection{Data extraction and outcomes}

The following information regarding each eligible study was recorded: authors' names, journal, year of publication, country/countries in which the study was undertaken, the mucin glycoprotein that was under investigation, and the method used to define each mucin glycoprotein's role in apoptosis.

\subsection{Analysis}

The results of all eligible studies were grouped together by the organ involved. The association between apoptosis, cell growth, invasion, migration, adhesion, and clonogenicity in vitro as well as tumor growth, tumorigenicity, and metastasis in vivo and each mucin glycoprotein investigated have been described. Where relevant, the signaling pathways involved have also been described.

\section{Results}

\subsection{Literature review}

The initial search yielded 2031 papers; this was reduced to 1297 after duplicates were removed with a further 1115 papers 
excluded by title and abstract alone leaving 182 manuscripts for full-text review; 92 articles were deemed ineligible after full-text review and the remaining 90 articles were deemed suitable for inclusion in the systematic review [30, 31, 35-122]. Of note, one of these articles investigated the role of apoptosis in two separate epithelial cancers [63]. The reasons as to why the articles were excluded are listed in the PRISMA flow diagram (Fig. 1). The details of the papers that were included in the review are available in Table 1.

\subsection{Appendiceal tumors}

One study looked at the association of MUC2 expression and apoptosis in an appendiceal tumor model [35]. Dilly et al. used an in vitro and an in vivo patient-derived xenograft (PDX) model to determine the significance of MUC2 expression and apoptosis in appendiceal pseudomyxoma peritonei. Celecoxib was used to reduce MUC2 mRNA and MUC2 protein expression. Reduced expression of MUC2 was associated with significantly increased apoptosis when compared to the nontreated cell line and PDX model.

\subsection{Breast cancer}

Twenty papers were available that investigated the link between mucin glycoproteins and breast cancer [30, 36-41, 62, 65-76]. MUC1 was the glycoprotein of interest in 10 of the 20 available papers. Li et al. found that MUC1-cytoplasmic domain (CD) overexpression was associated with significantly reduced apoptosis. The MUC1-CD transgenic mice in this

Fig. 1 PRISMA flow diagram

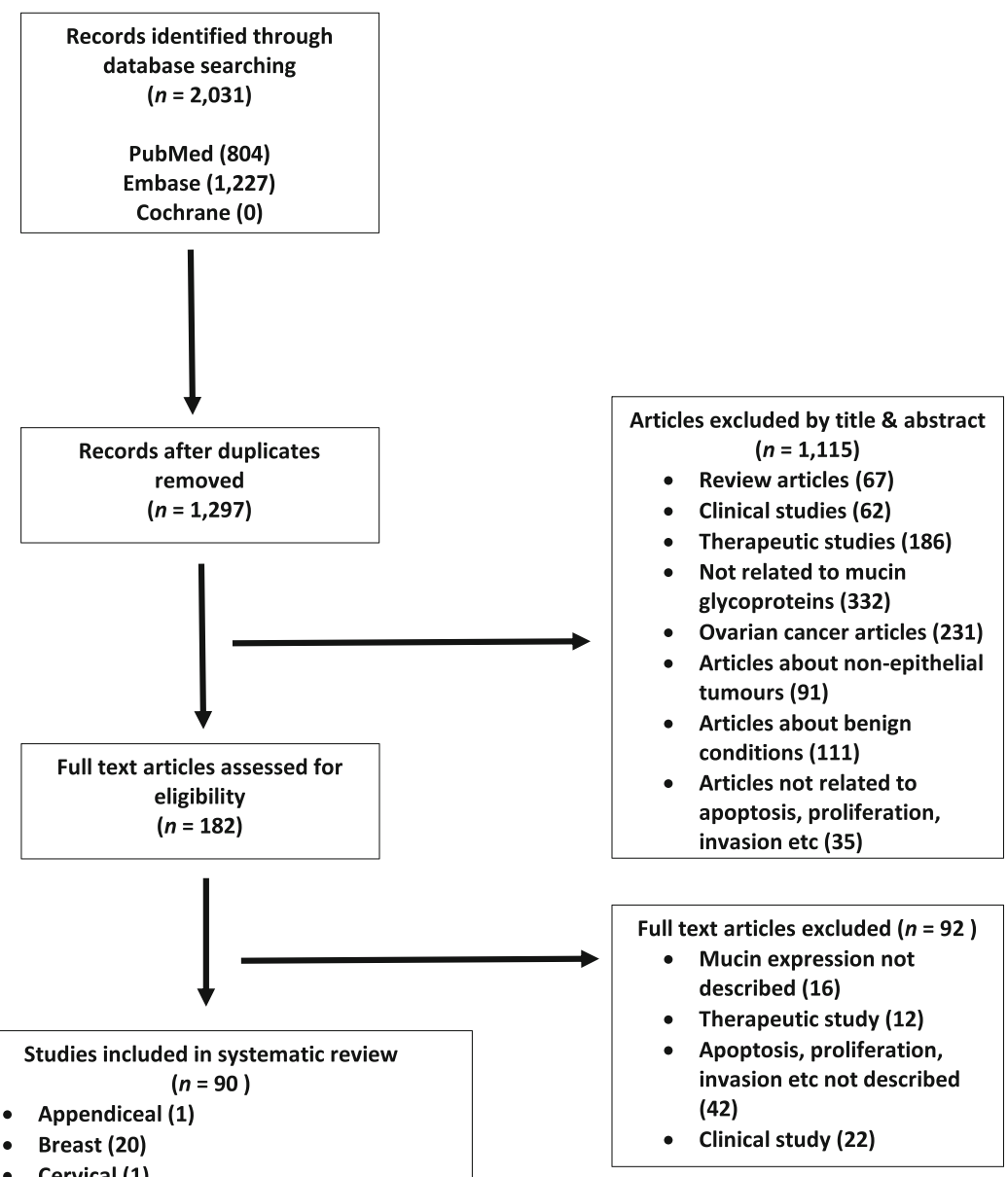

- Breast (20)

Clinical study (22)

- Colorectal (7)

- Esophageal (2)

- Gastric (5)

- Head \& Neck (1)

- Hepatocellular (3)

- Lung (8)

- Multiple (1)

- Colorectal \& cervical (1)

- Pancreas (31)

- Renal (3)

- Cancer Stem Cells (7) 
Table 1 Characteristics of the studies included

\begin{tabular}{|c|c|c|c|c|c|c|}
\hline 1st author & Year & Country & Cancer & MUC & Model used & Outcome \\
\hline Dilly A.K. & 2017 & USA & Appendix & MUC2 & In vitro and in vivo & $\begin{array}{l}\text { MUC2 expression inhibits } \\
\text { apoptosis }\end{array}$ \\
\hline Li Y. & 2018 & China & Breast & MUC1 & Transgenic mice & $\begin{array}{l}\text { MUC1 expression inhibits } \\
\text { apoptosis }\end{array}$ \\
\hline Zhao Q. & 2014 & UK, USA, and Netherlands & Breast & MUC1 & In vitro & $\begin{array}{l}\text { MUC1 expression inhibits } \\
\text { apoptosis }\end{array}$ \\
\hline Hattrup C.L. & 2006 & USA & Breast & MUC1 & In vitro & $\begin{array}{l}\text { MUC1 knockdown increases } \\
\text { apoptosis }\end{array}$ \\
\hline Schroeder J.A. & 2004 & USA & Breast & MUC1 & Transgenic mice & $\begin{array}{l}\text { MUC1 expression inhibits } \\
\text { apoptosis }\end{array}$ \\
\hline Fessler S.P. & 2009 & USA & Breast & MUC1* & In vitro & $\begin{array}{l}\text { MUC1* causes resistance to } \\
\text { trastuzumab }\end{array}$ \\
\hline Maeda T. & 2018 & USA & Breast & MUC1-C & In vitro and in vivo & $\begin{array}{l}\text { MUC1-C downregulation } \\
\text { suppresses PD-L1 } \\
\text { expression in TNBC cells }\end{array}$ \\
\hline Alam M. & 2014 & USA & Breast & MUC1-C & In vitro and in vivo & $\begin{array}{l}\text { MUC1-C is important for } \\
\text { breast cancer cell growth } \\
\text { in vitro and in vivo }\end{array}$ \\
\hline Raina D. & 2014 & USA & Breast & MUC1-C & In vitro and in vivo & $\begin{array}{l}\text { MUC1-C induces resistance } \\
\text { to trastuzumab }\end{array}$ \\
\hline Kharbanda A. & 2013 & USA & Breast & MUC1-C & In vitro and in vivo & $\begin{array}{l}\text { MUC1-C induces resistance } \\
\text { to tamoxifen through } \\
\text { upregulation of p-AKT }\end{array}$ \\
\hline Uchida Y. & 2013 & USA & Breast & MUC1-C & In vitro & $\begin{array}{l}\text { MUC1-C blocks the } \\
\text { apoptotic response }\end{array}$ \\
\hline Astashchanka A. & 2018 & USA & Breast & MUC2 & In vitro and in vivo & $\begin{array}{l}\text { MUC2 inhibits apoptosis, } \\
\text { increases proliferation, } \\
\text { decreases sensitivity to } \\
\text { chemotherapy, and } \\
\text { facilitates metastasis }\end{array}$ \\
\hline $\begin{array}{l}\text { Rowson-Hodel } \\
\text { A.R. }\end{array}$ & 2018 & USA & Breast & MUC4 & In vivo & MUC4 facilitates metastasis \\
\hline Mukhopadhyay P. & 2013 & USA & Breast & MUC4 & In vitro and in vivo & $\begin{array}{l}\text { MUC4 promotes } \\
\text { proliferation, growth, } \\
\text { migration, invasion, } \\
\text { tumorigenesis, and } \\
\text { metastasis }\end{array}$ \\
\hline Chen A.C. & 2012 & USA & Breast & MUC4 & In vivo & $\begin{array}{l}\text { MUC4 causes resistance to } \\
\text { endocrine and } \\
\text { HER2-targeted therapies }\end{array}$ \\
\hline Workman H.C. & 2009 & USA & Breast & MUC4 & In vitro & $\begin{array}{l}\text { MUC4 expression inhibits } \\
\text { apoptosis }\end{array}$ \\
\hline Garcia E.P. & 2016 & Uruguay & Breast & MUC5B & In vitro & $\begin{array}{l}\text { MUC5B causes } \\
\text { chemoresistance }\end{array}$ \\
\hline Valque $\mathrm{H}$. & 2012 & France & Breast & MUC5B & In vitro and in vivo & $\begin{array}{l}\text { MUC5B promotes } \\
\text { proliferation and invasion } \\
\text { in vitro and enhances } \\
\text { growth and cell } \\
\text { dissemination in vivo }\end{array}$ \\
\hline Liu Q. & 2016 & China & Breast & MUC16 & In vitro and in vivo & $\begin{array}{l}\text { MUC16 promotes } \\
\text { proliferation, migration, } \\
\text { and invasion in vitro. } \\
\text { MUC16 enhances } \\
\text { tumorigenesis and } \\
\text { metastasis in vivo }\end{array}$ \\
\hline Lakshmanan I. & 2012 & USA & Breast & MUC16 & In vitro & $\begin{array}{l}\text { MUC16 expression inhibits } \\
\text { apoptosis }\end{array}$ \\
\hline Reinartz S. & 2012 & Germany & Breast & MUC16 & In vitro & $\begin{array}{l}\text { MUC16 promotes } \\
\text { proliferation and inhibits } \\
\text { apoptosis }\end{array}$ \\
\hline Jin W. & 2017 & China & Cervical & MUC1 & In vitro & $\begin{array}{l}\text { MUC1 expression inhibits } \\
\text { apoptosis }\end{array}$ \\
\hline Chen Q. & 2013 & China & Colorectal & MUC1 & In vitro & $\begin{array}{l}\text { MUC1 expression inhibits } \\
\text { apoptosis }\end{array}$ \\
\hline Raina D. & 2006 & USA & Colorectal & MUC1 & In vitro & \\
\hline
\end{tabular}


Table 1 (continued)

\begin{tabular}{|c|c|c|c|c|c|c|}
\hline 1st author & Year & Country & Cancer & MUC & Model used & Outcome \\
\hline & & & & & & $\begin{array}{l}\text { MUC1 expression inhibits } \\
\text { apoptosis }\end{array}$ \\
\hline Ren J. & 2004 & USA & Colorectal & MUC1 & In vitro and in vivo & $\begin{array}{l}\text { MUC1 expression inhibits } \\
\text { apoptosis }\end{array}$ \\
\hline Das S. & 2016 & USA & Colorectal & MUC4 & In vivo & $\begin{array}{l}\text { MUC4 increases tumor } \\
\text { burden and the percentage } \\
\text { of Ki6 } 67^{+} \text {nuclei }\end{array}$ \\
\hline Zhu X. & 2016 & China & Colorectal & MUC5AC & In vitro & $\begin{array}{l}\text { MUC5AC expression } \\
\text { inhibits apoptosis }\end{array}$ \\
\hline Sheng Y.H. & 2017 & Australia & Colorectal & MUC13 & In vitro and in vivo & $\begin{array}{l}\text { MUC13 expression inhibits } \\
\text { apoptosis }\end{array}$ \\
\hline Gupta B.K. & 2014 & USA & Colorectal & MUC13 & In vitro & $\begin{array}{l}\text { MUC13 promotes cell } \\
\text { growth, colony formation, } \\
\text { migration, and invasion } \\
\text { in vitro }\end{array}$ \\
\hline Gronnier C. & 2014 & France & Esophageal & MUC1 & In vitro and in vivo & $\begin{array}{l}\text { MUC1 increase proliferation, } \\
\text { migration, and invasion } \\
\text { in vitro and increases } \\
\text { tumor size in vivo }\end{array}$ \\
\hline Bruyère E. & 2011 & France & Esophageal & MUC4 & In vitro and in vivo & $\begin{array}{l}\text { MUC4 increases } \\
\text { proliferation, migration, } \\
\text { and tumor growth }\end{array}$ \\
\hline Deng M. & 2013 & China & Gastric & MUC1 & In vitro & $\begin{array}{l}\text { MUC1 causes resistance to } \\
\text { trastuzumab }\end{array}$ \\
\hline Costa N.R. & 2011 & Portugal and USA & Gastric & MUC1 & In vitro & $\begin{array}{l}\text { MUC1 expression inhibits } \\
\text { apoptosis }\end{array}$ \\
\hline Shi M. & 2013 & China & Gastric & MUC4 & In vitro and in vivo & $\begin{array}{l}\text { MUC4 causes resistance to } \\
\text { trastuzumab }\end{array}$ \\
\hline Senapati S. & 2008 & USA & Gastric & MUC4 & In vitro and in vivo & $\begin{array}{l}\text { MUC4 increases cell motility } \\
\text { in vitro and } \\
\text { tumorigenicity in vivo }\end{array}$ \\
\hline Lahdaoui F. & 2017 & France & Gastric & MUC5B & In vitro and in vivo & $\begin{array}{l}\text { MUC5B increases } \\
\text { proliferation, migration, } \\
\text { and invasion }\end{array}$ \\
\hline Macha M.A. & 2015 & USA & Head and neck & MUC 4 & In vitro and in vivo & $\begin{array}{l}\text { MUC4 increases growth } \\
\text { in vitro and in vivo } \\
\text { decreases cell senescence }\end{array}$ \\
\hline YI F.T. & 2017 & China & Hepatocellular & MUC1 & In vitro & $\begin{array}{l}\text { MUC1 expression inhibits } \\
\text { apoptosis }\end{array}$ \\
\hline Yuan H. & 2015 & China & Hepatocellular & MUC1 & In vitro & $\begin{array}{l}\text { MUC1 expression inhibits } \\
\text { apoptosis }\end{array}$ \\
\hline Li Q. & 2014 & China & Hepatocellular & MUC1 & In vitro & $\begin{array}{l}\text { MUC1 expression inhibits } \\
\text { apoptosis }\end{array}$ \\
\hline Xu T. & 2017 & China & Lung & MUC1 & In vitro & $\begin{array}{l}\text { MUC1 expression inhibits } \\
\text { apoptosis }\end{array}$ \\
\hline Xu X. & 2014 & USA & Lung & MUC1 & In vitro & $\begin{array}{l}\text { MUC1 expression inhibits } \\
\text { apoptosis }\end{array}$ \\
\hline Gao J. & 2009 & USA & Lung & MUC1 & In vitro & $\begin{array}{l}\text { MUC1 expression inhibits } \\
\text { apoptosis }\end{array}$ \\
\hline Raina D. & 2011 & USA & Lung & MUC1-C & In vitro and in vivo & $\begin{array}{l}\text { MUC1-C promotes cell } \\
\text { growth in vitro and tumor } \\
\text { growth in vivo }\end{array}$ \\
\hline Majhi P.D. & 2013 & USA & Lung & MUC4 & In vitro & $\begin{array}{l}\text { MUC4 decreases } \\
\text { proliferation }\end{array}$ \\
\hline Lakshmanan I. & 2016 & USA & Lung & MUC5AC & In vitro & $\begin{array}{l}\text { MUC5AC plays a role in cell } \\
\text { migration }\end{array}$ \\
\hline Kanwal M. & 2018 & China & Lung & MUC16 & In vitro and in vivo & $\begin{array}{l}\text { MUC16 promotes growth, } \\
\text { migration, invasion, and } \\
\text { resistance to cisplatin }\end{array}$ \\
\hline Lakshmanan I. & 2017 & USA & Lung & MUC16 & In vitro and in vivo & $\begin{array}{l}\text { MUC16 increases growth } \\
\text { rate, migration, and } \\
\text { resistance to cisplatin and } \\
\text { gemcitabine in vitro and } \\
\text { increases tumor growth }\end{array}$ \\
\hline
\end{tabular}


Table 1 (continued)

\begin{tabular}{|c|c|c|c|c|c|c|}
\hline 1st author & Year & Country & Cancer & MUC & Model used & Outcome \\
\hline & & & & & & in vivo \\
\hline Yin L. & 2003 & USA & $\begin{array}{l}\text { Multiple } \\
\text { (colorectal and } \\
\text { cervical) }\end{array}$ & MUC1 & In vitro & $\begin{array}{l}\text { MUC1 expression inhibits } \\
\text { apoptosis }\end{array}$ \\
\hline Grover P. & 2018 & USA & Pancreatic & MUC1 & In vitro & $\begin{array}{l}\text { MUC1 expression inhibits } \\
\text { apoptosis }\end{array}$ \\
\hline Zhao P. & 2017 & China & Pancreatic & MUC1 & In vitro & $\begin{array}{l}\text { MUC1 expression inhibits } \\
\text { apoptosis }\end{array}$ \\
\hline Trehoux S. & 2015 & France & Pancreatic & MUC1 & In vitro & $\begin{array}{l}\text { MUC1 expression inhibits } \\
\text { apoptosis }\end{array}$ \\
\hline Trehoux S. & 2015 & France & Pancreatic & MUC1 & In vitro and in vivo & $\begin{array}{l}\text { MUC1 increases } \\
\text { proliferation, migration, } \\
\text { and invasion in vitro and } \\
\text { increases tumor size } \\
\text { in vivo. It also increases } \\
\text { resistance to gemcitabine }\end{array}$ \\
\hline Nath S. & 2013 & USA & Pancreatic & MUC1 & In vitro & $\begin{array}{l}\text { MUC1 induces resistance to } \\
\text { chemotherapy }\end{array}$ \\
\hline Roy L.D. & 2011 & USA & Pancreatic & MUC1 & In vitro and in vivo & $\begin{array}{l}\text { MUC1 enhances } \\
\text { invasiveness by inducing } \\
\text { epithelial to mesenchymal } \\
\text { transition }\end{array}$ \\
\hline Jahan R. & 2018 & USA & Pancreatic & MUC4 & In vitro and in vivo & $\begin{array}{l}\text { MUC4/X increases } \\
\text { proliferation, invasion, } \\
\text { migration, clonogenicity, } \\
\text { and adhesion in vitro. } \\
\text { MUC4/X increases tumor } \\
\text { size in vivo }\end{array}$ \\
\hline Pai P. & 2016 & USA & Pancreatic & MUC4 & In vitro and in vivo & $\begin{array}{l}\text { MUC4 increases migration } \\
\text { in vitro. In vivo, it results } \\
\text { in increased primary } \\
\text { tumor size and metastases }\end{array}$ \\
\hline Lahdaoui F. & 2015 & France & Pancreatic & MUC4 & In vitro and in vivo & $\begin{array}{l}\text { MUC4 increases } \\
\text { proliferation and cell } \\
\text { migration in vitro and } \\
\text { increases tumor size } \\
\text { in vivo }\end{array}$ \\
\hline Lakshmanan I. & 2015 & USA & Pancreatic & MUC4 & In vitro & $\begin{array}{l}\text { HER3 and MUC4 interact to } \\
\text { promote proliferation in } \\
\text { pancreatic cancer cells }\end{array}$ \\
\hline Seshacharyulu P. & 2014 & USA & Pancreatic & MUC4 & In vitro and in vivo & $\begin{array}{l}\text { MUC4 increases } \\
\text { proliferation, migration, } \\
\text { and survival in vitro and } \\
\text { increases tumor burden } \\
\text { and metastasis in vivo }\end{array}$ \\
\hline Skrypek N. & 2013 & France & Pancreatic & MUC4 & In vitro & $\begin{array}{l}\text { MUC4 inhibits apoptosis and } \\
\text { decreases sensitivity to } \\
\text { gemcitabine }\end{array}$ \\
\hline Momi N. & 2013 & USA & Pancreatic & MUC4 & In vitro and in vivo & $\begin{array}{l}\text { MUC4 increases cell } \\
\text { migration }\end{array}$ \\
\hline Rachagani S. & 2012 & USA & Pancreatic & MUC4 & In vitro and in vivo & $\begin{array}{l}\text { MUC4 increases motility and } \\
\text { invasion in vivo and } \\
\text { tumorigenicity and } \\
\text { metastasis in vivo }\end{array}$ \\
\hline Jonckheere N. & 2012 & France and USA & Pancreatic & MUC4 & In vitro & $\begin{array}{l}\text { MUC4 does not inhibit } \\
\text { apoptosis }\end{array}$ \\
\hline Wissniowski T.T & 2012 & Germany & Pancreatic & MUC4 & In vitro & $\begin{array}{l}\text { MUC4 expression increases } \\
\text { resistance to gemcitabine }\end{array}$ \\
\hline Senapati S. & 2012 & USA & Pancreatic & MUC4 & In vitro and in vivo & $\begin{array}{l}\text { MUC4-NIDO domain } \\
\text { promoted breaching of } \\
\text { basement membrane } \\
\text { integrity and enhances } \\
\text { invasiveness }\end{array}$ \\
\hline Torres M.P. & 2010 & USA & Pancreatic & MUC4 & In vitro & \\
\hline
\end{tabular}


Table 1 (continued)

\begin{tabular}{|c|c|c|c|c|c|c|}
\hline 1st author & Year & Country & Cancer & MUC & Model used & Outcome \\
\hline & & & & & & $\begin{array}{l}\text { MUC4 decreases apoptosis } \\
\text { and increases motility and } \\
\text { migration of pancreatic } \\
\text { cancer cells }\end{array}$ \\
\hline Bafna S. & 2009 & USA & Pancreatic & MUC4 & In vitro & $\begin{array}{l}\text { MUC4 expression inhibits } \\
\text { apoptosis }\end{array}$ \\
\hline Chaturvedi P. & 2007 & USA & Pancreatic & MUC4 & In vitro & $\begin{array}{l}\text { MUC4 expression inhibits } \\
\text { apoptosis }\end{array}$ \\
\hline Moniaux N. & 2007 & USA & Pancreatic & MUC4 & In vitro and in vivo & $\begin{array}{l}\text { MUC4 increases growth, } \\
\text { motility, and invasiveness. } \\
\text { MUC4 enhances } \\
\text { tumorigenicity in vivo }\end{array}$ \\
\hline Singh A.P. & 2004 & USA & Pancreatic & MUC4 & In vitro and in vivo & $\begin{array}{l}\text { MUC4 increases growth, } \\
\text { clonogenic ability, and } \\
\text { motility in vitro. MUC4 } \\
\text { enhances growth and } \\
\text { metastatic properties } \\
\text { in vivo }\end{array}$ \\
\hline Hoshi H. & 2013 & Japan & Pancreatic & MUC5AC & In vitro & $\begin{array}{l}\text { MUC5AC expression } \\
\text { inhibits apoptosis }\end{array}$ \\
\hline Hoshi H. & 2011 & Japan & Pancreatic & MUC5AC & In vitro and in vivo & $\begin{array}{l}\text { MUC5AC promotes } \\
\text { tumorigenicity and growth } \\
\text { in vivo }\end{array}$ \\
\hline Yamazoe S. & 2010 & Japan & Pancreatic & MUC5AC & In vitro & $\begin{array}{l}\text { MUC5AC promotes } \\
\text { adhesion and invasion of } \\
\text { pancreatic cancer cells } \\
\text { in vitro }\end{array}$ \\
\hline Chauhan S.C. & 2012 & USA & Pancreatic & MUC13 & In vitro and in vivo & $\begin{array}{l}\text { MUC13 promotes motility, } \\
\text { invasion, proliferation, } \\
\text { and clonogenicity in vitro. } \\
\text { MUC13 promotes tumor } \\
\text { growth and decreases } \\
\text { survival in vivo }\end{array}$ \\
\hline Muniyan S. & 2016 & USA & Pancreatic & MUC16 & In vitro and in vivo & $\begin{array}{l}\text { MUC16 increases } \\
\text { proliferation, colony } \\
\text { formation, and migration } \\
\text { in vivo. MUC16 increases } \\
\text { tumor formation and } \\
\text { metastasis in vivo }\end{array}$ \\
\hline Das S. & 2015 & USA & Pancreatic & MUC16 & In vitro and in vivo & $\begin{array}{l}\text { MUC16-Cter inhibits } \\
\text { apoptosis }\end{array}$ \\
\hline Shukla S.K. & 2015 & USA & Pancreatic & MUC16 & In vitro & $\begin{array}{l}\text { MUC16 increases migration } \\
\text { and invasion through } \\
\text { interaction with mTOR }\end{array}$ \\
\hline Shimizu A. & 2012 & Japan & Pancreatic & MUC16 & In vitro & $\begin{array}{l}\text { MUC16 increases migration } \\
\text { and invasion of pancreatic } \\
\text { cells in vitro }\end{array}$ \\
\hline Lee $\mathrm{J}$. & 2016 & Korea & Pancreatic & MUC5B and MUC16 & In vitro & $\begin{array}{l}\text { MUC5B and MUC16 } \\
\text { promote migration and } \\
\text { survival of pancreatic } \\
\text { cancer cells in vitro }\end{array}$ \\
\hline Bouillez A. & 2014 & France & $\mathrm{RCC}$ & MUC1 & In vitro & $\begin{array}{l}\text { MUC1 increases migration } \\
\text { and cell viability }\end{array}$ \\
\hline Aubert S. & 2009 & France & $\mathrm{RCC}$ & MUC1 & In vitro & $\begin{array}{l}\text { MUC1 increases migration } \\
\text { and invasion of renal } \\
\text { cancer cells in vitro }\end{array}$ \\
\hline Sheng Y. & 2017 & Australia & $\mathrm{RCC}$ & MUC13 & In vitro & $\begin{array}{l}\text { MUC13 expression inhibits } \\
\text { apoptosis }\end{array}$ \\
\hline Wang R. & 2018 & China & Cancer stem cells & MUC1 & In vitro & $\begin{array}{l}\text { MUC1 promotes } \\
\text { proliferation, self-renewal } \\
\text { and invasion of breast } \\
\text { cancer stem cells }\end{array}$ \\
\hline
\end{tabular}

Hiraki M.

2017 USA

Cancer stem cells

MUC1

In vitro 
Table 1 (continued)

\begin{tabular}{|c|c|c|c|c|c|c|}
\hline 1st author & Year & Country & Cancer & MUC & Model used & Outcome \\
\hline & & & & & & $\begin{array}{l}\text { MUC1 promotes BMl1 } \\
\text { transcription and inhibits } \\
\text { BMl1 downregulation }\end{array}$ \\
\hline Huang W.C. & 2016 & Taiwan & Cancer stem cells & MUC1 & In vitro & $\begin{array}{l}\text { MUC1 promotes } \\
\text { tumor-associated } \\
\text { macrophage-induced lung } \\
\text { cancer stem cell } \\
\text { progression }\end{array}$ \\
\hline Zhou N. & 2015 & China & Cancer stem cells & MUC1 & In vitro and in vivo & $\begin{array}{l}\text { Cancer stem-like cells are } \\
\text { associated with increased } \\
\text { MUC1 expression }\end{array}$ \\
\hline Alam M. & 2013 & USA & Cancer stem cells & MUC1 & In vitro & $\begin{array}{l}\text { MUC1 promotes activity in } \\
\text { breast CSC }\end{array}$ \\
\hline Engelmann & 2008 & USA & Cancer stem cells & MUC1 & In vitro & $\begin{array}{l}\text { Breast cancer stem cells } \\
\text { express MUC1 }\end{array}$ \\
\hline Mimeault M. & 2010 & USA & Cancer stem cells & MUC4 & In vitro & $\begin{array}{l}\text { MUC4 increases } \\
\text { proliferation and invasion. } \\
\text { It reduces } \\
\text { gemcitabine-induced } \\
\text { apoptosis }\end{array}$ \\
\hline
\end{tabular}

$R C C$, renal cell carcinoma; $C S C$, cancer stem cells

study had increased expression of the anti-apoptotic protein Bcl-xL and alterations in NF-kB signaling. Similarly, Schroeder et al. showed that MUC1 overexpression resulted in a reduced rate of apoptosis in transgenic mice and was integral in the formation of mammary gland tumors. Hattrup et al. demonstrated that MUC1 gene silencing of breast cancer cell lines using small interfering RNA (siRNA) resulted in increased apoptosis, again demonstrating an inverse relationship between MUC1 expression and apoptosis. Zhao et al. demonstrated that MUC1-positive transfectants of human breast HBL-100 epithelial cells showed 6.1 times less apoptosis compared to the same cell line not overexpressing MUC1. Fessler et al. very nicely demonstrated that antagonists of the cleaved $\mathrm{MUC1}$ protein, $\mathrm{MUC1}{ }^{*}$, can overcome the resistance to trastuzumab seen in cell lines overexpressing MUC1*. Maeda et al. showed that targeting the MUC1 subunit, MUC1-C, suppresses PD-L1 expression in TNBC cells and results in an increase in $\mathrm{CD}^{+} \mathrm{T}$ cells and tumor cell killing in vivo. Alam et al. demonstrated that breast cancer cells are dependent on MUC1-C for growth in vitro and in vivo. Kharbanda et al. found that oncogenic MUC1-C promotes tamoxifen resistance through upregulation of p-AKT. Raina et al. showed that silencing of MUC1-C reversed resistance to trastuzumab resistance and that MUC1-C contributed to the constitutive activation of the HER2 pathway. Uchida et al. found that MUC1-C blocks the apoptotic response and this blockade could be overcome with a MUC1-C inhibitor.

Astashchanka et al. showed that MUC2 knockdown cell lines had increased apoptosis and decreased proliferation compared to the wild-type cell lines. Furthermore, the authors demonstrated that decreased MUC2 levels increases sensitivity to chemotherapy. They also showed that metastatic cells may be dependent on MUC2 using an in vivo mouse model. Workman et al. studied the association between MUC4 and apoptosis in a breast cancer cell line. They established that MUC4 expression was negatively correlated with apoptosis. They showed that the anti-apoptotic effect of MUC4 was dependent on ErbB2 signaling in a breast cancer cell line. Rowson-Hodel et al. demonstrated that MUC4 knockout reduced lung metastasis in an in vivo model. The authors suggested that MUC4 might facilitate metastasis by promoting the association of circulating tumor cells with blood cells that appear to augment tumor cell survival in circulation. Mukhopadhyay et al. showed that MUC4 promotes proliferation and growth in triple negative breast cancer (TNBC) cell lines; furthermore, it upregulates the EGFR family of proteins and downstream signaling associated with these proteins. The authors also showed that MUC4 enhances migratory and invasive potential. In an in vivo model, MUC4 was shown to promote tumorigenesis and metastasis. Chen et al. found that MUC4 overexpression was associated with resistance to endocrine and HER2-targeted therapies in vivo. Garcia et al. used short hairpin RNA (shRNA) to knockdown the expression of MUC5B in a breast cancer cell line. They showed that reduced expression of MUC5B decreased cell adhesion, cell growth, and clonogenic ability of breast cancer cells but does not increase apoptosis. They also showed that MUC5B was associated with a worse response to chemotherapy and reducing the expression of MUC5B increases chemosensitivity. Valque et al. highlighted how MUC5B leads to aggressive behavior in breast cancer cells. They showed that MUC5B promoted the proliferation and invasion in vitro and enhanced growth and cell dissemination in vivo. Lakshmanan et al. showed that MUC16 expression inhibited TRAIL-mediated 
apoptosis in a breast cancer cell line. Downregulation of MUC16 resulted in increased apoptosis via the extrinsic apoptotic pathway. Reinartz et al. demonstrated that MUC16 gene silencing results in induction of apoptosis and suppression of proliferation in SKBR-3 breast cancer cell. Liu et al. found that MUC16 promotes migration, invasion and proliferation of breast cancer cells in vitro. They also found that MUC16 enhances tumorigenesis and metastasis in vivo.

\subsection{Cervical cancer}

Two papers were identified that looked at the role of mucin glycoproteins in cervical cancer [42, 63]. Jin et al. demonstrated that shRNA-based silencing of MUC1 in cervical cancer cells resulted in increased apoptosis when compared to control cells in response to paclitaxel. Yin et al. demonstrated that MUC1 overexpression in HeLA cells reduced the apoptotic response to $\mathrm{H}_{2} \mathrm{O}_{2}$.

\subsection{Colorectal cancer}

The literature review identified eight papers that studied the link between mucin glycoproteins and colorectal cancer $[43-46,63,64,77,78]$. Four of the eight papers focused on the role of MUC1. Chen et al. demonstrated that MUC1 expression blocked the apoptotic response through the JNK1 pathway in an in vitro model. The antiapoptotic effects of MUC1 were reversed by reducing MUC1 expression. Ren et al. showed that MUC1 expression attenuated apoptosis induced by activation of both the intrinsic and extrinsic pathways. Downregulation of MUC1 was shown to sensitize cancer cells to apoptosis induced by chemotherapy both in vitro and in vivo. Yin et al. demonstrated that $\mathrm{H}_{2} \mathrm{O}_{2}$-induced apoptosis was significantly reduced in MUC1-positive compared to MUC1negative HCT116 cells. Raina et al. showed that MUC1 overexpression in HCT-116 cells attenuated the internal apoptotic pathway when compared to HCT-116 empty vector-transfected control cells. Das et al. showed that $\mathrm{MUC}^{-/-}$mice had significantly reduced tumor burden compared to wild-type mice and a decreased percentage of $\mathrm{Ki}^{+} 7^{+}$nuclei suggesting that MUC4 was critical to intestinal cell proliferation during tumorigenesis. Zhu et al. focused on MUC5AC in a colon cancer cell line. The authors demonstrated that expression of MUC5AC resulted in low levels of apoptosis. Inhibition of MUC5AC using siRNA enhanced apoptosis and arrested the cell cycle in G1. Sheng et al. studied the effects of MUC13 in in vitro and in vivo models. They demonstrated that MUC13 inhibited intrinsic and extrinsic apoptosis by promoting the NF-KB pathway. Silencing of MUC13 using siRNA resulted in increased apoptosis in the in vivo model. Gupta et al. explored the role of MUC13 in a colon cancer cell line and found that MUC13 increased cell growth, colony formation, migration, and invasion. MUC13 overexpressing cells showed increased HER2 and P-Erk expression, and they also demonstrated that MUC13 expression was increased via activation of the JAK2/STAT5 signaling pathway.

\subsection{Esophageal cancer}

Two papers were identified that investigated the role of mucin glycoproteins in esophageal cancer [79, 80]. Gronnier et al. used MUC1 knockdown esophageal cancer cells to demonstrate that increased MUC1 levels were associated with proliferation, migration, and invasion in vitro and increased tumor size in vivo. Bruyère et al. showed that an esophageal cancer cell line with MUC4 knockout had less proliferation and migration than the wild-type cell line; furthermore, using an in vivo model, they showed that there was a significant decrease in tumor size in cells not expressing MUC4.

\subsection{Gastric cancer}

Five papers were identified that studied the effects of mucin glycoprotein expression on gastric cancer [31, 41, 47, 81-83]. Using a human cell line from a diffuse type gastric cancer, Costa et al. found that MUC1 expression decreased apoptosis. They used shRNA to decrease the expression of MUC1 and this resulted in increased apoptosis when compared to the control cell line. Deng et al. showed that silencing the expression of MUC1 in a gastric cancer cell line can overcome resistance to trastuzumab. Senapati et al. ectopically expressed MUC4 in a poorly differentiated gastric nonsignet ring cell line. MUC4 overexpressing cells showed a significant increase in cell motility and a decrease in cellular aggregation when compared to the vector-transfected cells. Animals transplanted with the MUC4 overexpressing cells had a greater incidence of tumors in comparison to an empty vector control. Shi et al. found that MUC4 was upregulated by catecholamine-induced $B 2$-adrenergic receptor activation via activation of STAT3 and ERK and this prevented trastuzumab from recognition of and binding to Her2. Lahdaoui et al. used the human gastric cancer cell line KATO-III to demonstrate that MUC5B knockdown led to decreased proliferation, migration, and invasion properties of the cell line. Using an in vivo xenograft, the authors also showed that MUC5Bdeficient cells had decreased tumor growth when compared with MUC5B-expressing cells.

\subsection{Head and neck cancer}

A single article was identified that investigated the role of mucin glycoproteins in head and neck cancer [84]. Macha et al. first demonstrated that MUC4 was upregulated in $78 \%$ 
of head and neck squamous cell (HNSCC) tissues compared with $10 \%$ positivity in benign samples. MUC4 knockdown in two HNSCC cell lines resulted in growth inhibition in vitro and in vivo and increased cell senescence. Nude mice implanted with knockdown cells into the floor of the mouth had significantly smaller tumors when compared to those implanted with control cells.

\subsection{Hepatocellular carcinoma}

Three articles that evaluated the association between MUC1 and apoptosis in hepatocellular carcinoma (HCC) were deemed eligible for inclusion in the study [48-50]. Yi et al. demonstrated that MUC1 was upregulated in HCC cells following irradiation. This overexpression inhibited irradiationinduced apoptosis by $>60 \%$. They showed that MUC1 overexpression inhibited apoptosis through activation of JAK2/ STAT3. Yuan et al. showed that MUC1 expression inhibited apoptosis in a HCC cell line. Using siRNA to silence MUC1, they showed that decreasing the expression of MUC1 induced apoptosis through mitochondrial and death receptor apoptotic pathways. Similarly, Li et al. used siRNA to silence MUC1 expression in a HCC cell line. They found that knockdown of MUC1 induced apoptosis and altered the $\beta$-catenin signaling pathway by blocking $\beta$-catenin translocation to the nucleus.

\subsection{Lung cancer}

Eight articles investigating the association between mucin glycoproteins and lung cancer were eligible for inclusion in the review [51-53, 85-89]. Xu et al. used siRNA to silence the expression of MUC1 in a nonsmall cell lung cancer (NSCLC) cell line. They showed that MUC1 downregulation promoted apoptosis. They also showed that MUC1 downregulation suppressed the AKT and MAPK signaling pathways. Similarly, $\mathrm{Xu}$ et al. demonstrated that MUC1 overexpression in lung cancer cell lines led to apoptotic resistance and chemoresistance. Using siRNA to silence MUC1 expression helped to overcome apoptosis and chemoresistance. Gao et al. also used a NSCLC cell line. They showed that MUC1 silencing using siRNA increased the levels of apoptosis and sensitized the cells to treatment with cisplatin. Raina et al. showed that lung cancer cells were dependent on MUC1-C for growth and treatment with a MUC1-C inhibitor in vivo resulted in tumor regression. Majhi et al. showed that MUC4 expression in lung cancer cell lines was associated with less proliferation and a less metastatic phenotype. Cells expressing MUC4 had upregulation of $\mathrm{p} 53$ leading to an accumulation of cells at the G2/M phase of cell cycle progression. In keeping with this finding, the authors demonstrated a decrease in MUC4 expression with increasing tumor stage in their patient cohort. Lakhsmanan et al. demonstrated that MUC5AC knockdown cells had significantly decreased migration in two lung cancer cell lines when compared to the scramble cells. The authors concluded that MUC5AC interacts with integrin $\beta 4$ and this interaction plays a role in lung cancer cell migration. In a separate paper, Lakshmanan et al. also used shRNAs to knockdown MUC16 in lung cancer cell lines. The authors demonstrated that MUC16 increased growth rate and migration in vitro and increased in vivo tumor growth. MUC16 also induced cisplatin and gemcitabine resistance by downregulation of p53. Kanwal et al. showed that MUC16 overexpression in lung cancer cell lines resulted in increased growth, migration, invasion, and increased resistance to cisplatin.

\subsection{Pancreatic cancer}

Thirty-one papers that elucidated an association between mucin glycoproteins and pancreatic cancer were included in the review [54-60, 99-122]. Grover et al. showed that MUC1 overexpressing pancreatic cancer cells were completely protected from TGF- $\beta 1$-induced apoptosis when compared to a control cell line. Zhao et al. showed that silencing of MUC1 using siRNA in a pancreatic cancer cell line induced apoptosis. Trehoux et al. used a retroviral infection to silence MUC1 expression in a pancreatic cancer cell line. They showed that MUC1 gene silencing increased apoptosis and conferred sensitivity to gemcitabine and FOLFIRINOX when compared to the MUC1 expressing cell line. Trehoux et al. also used miRNAs to regulate the expression of mucin glycoproteins. They decreased the expression of MUC1 using miR29a and miR-330-5p in pancreatic cancer cells. This inhibited cell proliferation, migration, and invasion, as well as this also sensitized pancreatic cancer cells to gemcitabine chemotherapy. In their in vivo studies, intratumoral injection of these two miRNAs in xenografted pancreatic tumors led to reduced tumor growth. Nath et al. found that MUC1 induced resistance in pancreatic cancer cells to gemcitabine and etoposide through enhanced expression of multidrug resistance genes such as $\mathrm{ABCC} 1, \mathrm{ABCC} 3$, and $\mathrm{ABCC} 5$. Roy et al. found that MUC1 enhances invasiveness of pancreatic cancer cells by inducing epithelial to mesenchymal transition.

Jonckheere et al. investigated the association between MUC4 expression and apoptosis in pancreatic cancer cell lines. MUC4 knockdown cells were obtained by retroviral infection with a plasmid. They found no difference in apoptosis between MUC4 expressing and MUC4 knockdown pancreatic cancer cells. MUC4 knockdown cells did, however, show decreased proliferation; in contrast to this, they were significantly more invasive. Bafna et al. found the opposite to be true with regard to MUC4. MUC4 was silenced in a pancreatic cancer cell line using siRNA. The MUC4silenced cells showed increased apoptosis in response to gemcitabine treatment when compared to the MUC4expressing cells. The authors provided evidence that MUC4 blocked the intrinsic apoptotic pathway. Chaturvedi et al. 
similarly showed that silencing of MUC4 using siRNA resulted in an increase in apoptosis in pancreatic cancer cells. Skrypek et al. demonstrated that MUC4 knockdown pancreatic cancer cells were more sensitive to gemcitabine chemotherapy when compared to wild-type pancreatic cancer cells. The authors showed that MUC4 knockdown pancreatic cells had decreased activation of the MAPK, JNK, and NF-KB pathways. Lahdaoui et al. used miR-219-1-3p to negatively regulate MUC4 expression, and this resulted in a decrease in cell proliferation and migration. Interestingly, when miR-219$1-3 p$ was injected into xenografted pancreatic tumors in mice, it resulted in decreased tumor growth and MUC4 expression. Jahan et al. showed that MUC4/X, a MUC4 splice variant, overexpression resulted in enhanced pancreatic cell proliferation, invasion, migration, clonogenicity, and adhesion. The authors also demonstrated that MUC4/X-overexpressing tumors implanted into the pancreas of athymic nude mice were significantly larger than wild-type tumors at 50 days post-implantation. Seshacharyulu et al. used the pan-EGFR inhibitors, canertinib and afatinib, to reduce MUC4 expression and its oncogenic functions in pancreatic cancer cells in vitro and in an in vivo model. Reduced expression of MUC4 resulted in decreased proliferation, migration, and survival of pancreatic cancer cells and reduced tumor burden and metastasis in the in vivo model. Lakshmanan et al. demonstrated that HER3/MUC4 had a positive role in HER2 low pancreatic cancer cells. Knockdown of HER3 using siRNA led to decreased proliferation leading the authors to conclude that HER3 interacts with MUC4 to promote proliferation in HER2 low pancreatic cancer cells. Pai et al. were able to demonstrate that $\beta$-catenin directly governs MUC4 in pancreatic cancer cells. Knockdown of $\beta$-catenin in pancreatic cancer cell lines resulted in reduced MUC4 transcript and protein. The knockdown cell lines showed decreased migration in vitro. After orthotopic implantation, the nude mice that were implanted with the knockdown cells had reduced primary tumor sizes and metastases compared to those mice implanted with the scrambled control cells. Rachagani et al. showed that MUC4 promotes invasion and metastasis by FGFR1 stabilization through $\mathrm{N}$-cadherin upregulation. MUC4 knockdown cells were associated with downregulation of FGFR1 and this led to a decrease in motility and invasion in vitro and decreased tumorigenicity and metastasis in vivo when compared with scramble vector-transfected cells. Momi et al. explored the interaction between nicotine, cigarette smoke, and pancreatic cancer. They demonstrated that cigarette smoke and nicotine upregulate MUC4 expression in pancreatic cancer cells. Nicotine-induced MUC4 expression increased the migratory potential of pancreatic cancer cells. In a mouse model, cigarette smoke increased pancreatic tumor weight and potentiated tumor metastasis. Moniaux et al. engineered a MUC4 complementary DNA construct called mini-MUC4 whose deduced protein is comparable with that of wild-type MUC4. Expression of this protein resulted in increased growth, motility, and invasiveness of pancreatic cancer cells in vitro. Furthermore, these cells were found to have enhanced tumorigenicity in an orthotopic xenograft nude mouse model. Senapati et al. demonstrated the importance of the nidogen-like (NIDO) domain of MUC4. The in vitro studies carried out by the authors showed that the NIDO domain contributes to the protein-protein interaction of MUC4 and thus promotes breaching of basement membrane integrity and spreading of cancer cells. Cells expressing MUC4 demonstrated enhanced invasiveness; interestingly, the absence of the NIDO domain had no effect on cell growth and motility. The authors concluded that the MUC4-NIDO domain significantly contributes to the MUC4-mediated metastasis of pancreatic cancer cells. Singh et al. silenced MUC4 expression in an aggressive and highly metastatic pancreatic cancer cell line. Decreased MUC4 expression resulted in diminished growth and clonogenic ability as well as motility in vitro and decreased tumor growth and metastatic properties in vivo. MUC4 downregulation correlated with reduced expression of Her2/neu. Torres et al. treated pancreatic cancer cells with thymoquinone, and this resulted in downregulation of MUC4 expression through the proteasomal pathway. This downregulation of MUC4 was associated with increased apoptosis, decreased motility, and decreased migration of pancreatic cancer cells. Wissniowski et al. showed that silencing of MUC4 increased the sensitivity of pancreatic cancer cells to gemcitabine.

Hoshi et al. found that MUC5AC expression resulted in less apoptosis in response to TRAIL when compared to the same cell line with MUC5AC knocked down using siRNA. In a separate study, Hoshi et al. demonstrated that MUC5AC knockdown cells resulted in less tumorigenicity and growth in vivo when compared to the wild-type cells. Yamazoe et al. used siRNA to knockdown MUC5AC in two pancreatic cancer cell lines. The knockdown cells showed significantly lower adhesion and invasion to extracellular matrix components compared to the wild-type cell lines. Furthermore, the expression of genes associated with adhesion and invasion such as integrins, matrix metalloproteinase-3, and VEGF was downregulated in MUC5AC-suppressed cells. Chauhan et al. investigated MUC13 in the setting of pancreatic cancer and demonstrated that MUC13 enhances motility, invasion, proliferation, and clonogenicity in vitro, while in vivo, it promotes tumor growth and reduces survival. MUC13 expression is positively correlated with upregulation of Her2, ERK, and PAK1 and downregulation of $\mathrm{p} 53$.

Das et al. determined that the carboxyl-terminal domain of MUC16 promotes G2/M block with apoptotic resistance in pancreatic cancer cells, and this is a property commonly ascribed to cancer stem cells. Muniyan et al. demonstrated that MUC16 knockdown cells have less proliferation, colony formation, and migration when compared to wild-type cells. 
MUC16 knockdown was shown to decrease tumor formation and metastasis in an orthotopic xenograft mouse model. Shukla et al. studied the role of MUC16 in pancreatic cancer and determined that MUC16 increases migration and invasion. MUC16 knockdown cells have reduced lactate secretion and supplementing the culture media with lactate restored the migration and invasion potential. The authors also demonstrated reduced mTOR activity in MUC16 knockdown cells, and this led to reduced expression of c-MYC, a downstream target of mTOR and a key player in cellular growth, proliferation, and metabolism. Ectopic expression of c-MYC in MUC16 knockdown cells restored the altered cellular physiology. Shimizu et al. showed that downregulation of MUC16 and inhibition of MUC16 binding resulted in reduced invasion and migration of pancreatic cancer cells in vitro. Lee et al. showed that transfection with siRNA for MUC5B and MUC16 inhibited the migration and survival of pancreatic cancer cells in vitro.

\subsection{Renal cell carcinoma}

Three papers were identified that evaluated the role of mucin glycoproteins in renal cell carcinoma (RCC) [61, 90, 91]. Bouillez et al. correlated MUC1 overexpression with an increase in migration and cell viability and a resistance to anoikis. Aubert et al. showed that MUC1 knockdown induced a significant reduction of invasion and migration in renal cancer cells. Using an RCC cell line, Sheng et al. silenced MUC13 using siRNA. The silencing of MUC13 was associated with an increase in apoptosis induced by sorafenib or sunitinib. They demonstrated that MUC13 promotion of cell growth and migration was dependent on activation of NF- $\mathrm{KB}$.

\subsection{Cancer stem cells}

Seven papers were identified that investigated the association between mucin glycoproteins and cancer stem cells [92-98]. Alam et al. demonstrated that MUC1 activates a signaling pathway involving ALDH1A1 which in turn promotes the induction of ALDH activity in breast cancer cells. ALDH activity is used as a marker of breast cancer stem cells, and hence, MUC1 has a positive effect on these cells. Huang et al. demonstrated that MUC1-silenced M2 tumor-associated macrophages (TAM) exhibited a significantly lower ability to promote lung cancer stem cell generation suggesting that MUC1 plays an important role in TAM-induced lung cancer stem cell generation. Wang et al. used a flavonoid named quercetin to reduce breast cancer stem cell proliferation, self-renewal, and invasiveness. The authors showed that downregulation of MUC1 was one of the mechanisms used by quercetin against breast cancer stem cells. Hiraki et al. found that BMl1 is overexpressed in breast and several other cancers and promotes self-renewal in cancer stem-like cells. The authors showed that MUC1-C drives BMl1 transcription by a MYC-dependent mechanism and blocks miR-200c-mediated downregulation of BMl1 expression thus linking MUC1-C to self-renewal in human carcinoma cells. Zhou et al. showed that tumor-associated macrophages exposed to apoptotic breast cancer cells induce an increase in cancer stem-like cells and their proliferative ability accompanied with an increase in MUC1 expression. Engelmann et al. showed that MUC1 is expressed in cancer stem/progenitor cells found in the MCF7 breast cancer cell line, and hence, these cells would be targets of MUC1-directed immunotherapy. Mimeault et al. showed that MUC4 expression in pancreatic cancer cells was associated with a higher resistance to the antiproliferative, anti-invasive, and apoptotic effects induced by gemcitabine. They also showed that MUC4 is expressed in the small $\mathrm{CD} 133^{+}$cell progenitor subpopulation as well as in their differentiated $\mathrm{CD} 133^{-}$progenies. MUC4 downregulation may partially reverse the resistance of $\mathrm{CD}_{133^{+}}$initiating cells to gemcitabine treatment.

\section{Discussion}

Our literature review identified 90 papers that looked at the association between mucin glycoproteins and epithelial cancers. The majority of these papers studied mucin glycoproteins in a cell culture setting; however, 40 had an in vivo component. MUC1 was the focus of 38 studies, MUC4 was the focus of 27 studies, MUC16 was the focus of 10 studies, MUC5AC was the focus of 5 studies, MUC5B and MUC13 had 4 studies devoted to their role in the apoptotic process, while MUC2 was analyzed in 2 studies. Firstly, our findings show that mucin glycoproteins appear to play a significant role in apoptosis, cell growth, invasion, migration, adhesion, and clonogenicity in vitro as well as tumor growth, tumorigenicity, and metastasis in vivo in epithelial-derived cancers. All 39 papers focusing on MUC1 demonstrated that overexpression of MUC1 either inhibited the apoptotic process when compared to the same cell lines not overexpressing MUC1 or enhanced proliferation, migration, invasion, and tumorigenicity. Furthermore, there was overwhelming evidence that MUC1 resulted in resistance to chemotherapy across many different cancer subtypes. The majority of the studies (25/27) evaluating MUC4 showed that in a similar fashion to MUC1, MUC4 appears to inhibit apoptosis and enhance proliferation, migration, and invasion. There is also strong evidence that MUC4 promotes resistance to chemotherapy. Interestingly, there was a single study that was unable to demonstrate a difference in apoptosis between MUC4overexpressing cells and MUC4 knockdown cells and a second study that showed that MUC4 expression resulted in decreased cell proliferation. MUC2, MUC5AC, MUC5B, MUC13, and MUC16 expression was shown to inhibit apoptosis and promote invasion, migration, adhesion, and chemoresistance. Based on our findings, it appears that there is strong evidence 
to show that aberrant mucin glycoprotein expression in cancer increases resistance to apoptosis, promotes aggressive features of malignant cells, and likely contributes to the chemoresistance demonstrated by some cancers.

Mucin glycoproteins appear to inhibit apoptosis and induce resistance to chemotherapy through diverse signaling pathways (Fig. 2). In breast cancer cell lines, MUC4 overexpression was shown to confer resistance to apoptosis through augmentation of ErbB2 signaling to regulate anti-apoptotic Bcl-2 family proteins and promote cellular survival under stressful conditions. MUC16 has been shown to interact with JAK2 in breast cancer cells and result in downstream activation of STAT3 which induces tumorigenesis. Interestingly, MUC1 has also been shown to promote radioresistance through activation of JAK2/STAT3 signaling in hepatocellular carcinoma. Conversely, in the setting of lung cancer, STAT3 has been shown to regulate the expression of MUC1 which drives cell survival and colony formation. In the setting of cervical cancer, MUC1 has been shown to enhance nuclear translocation of EGFR. In colorectal cancer, MUC13 appears to protect cells from death by
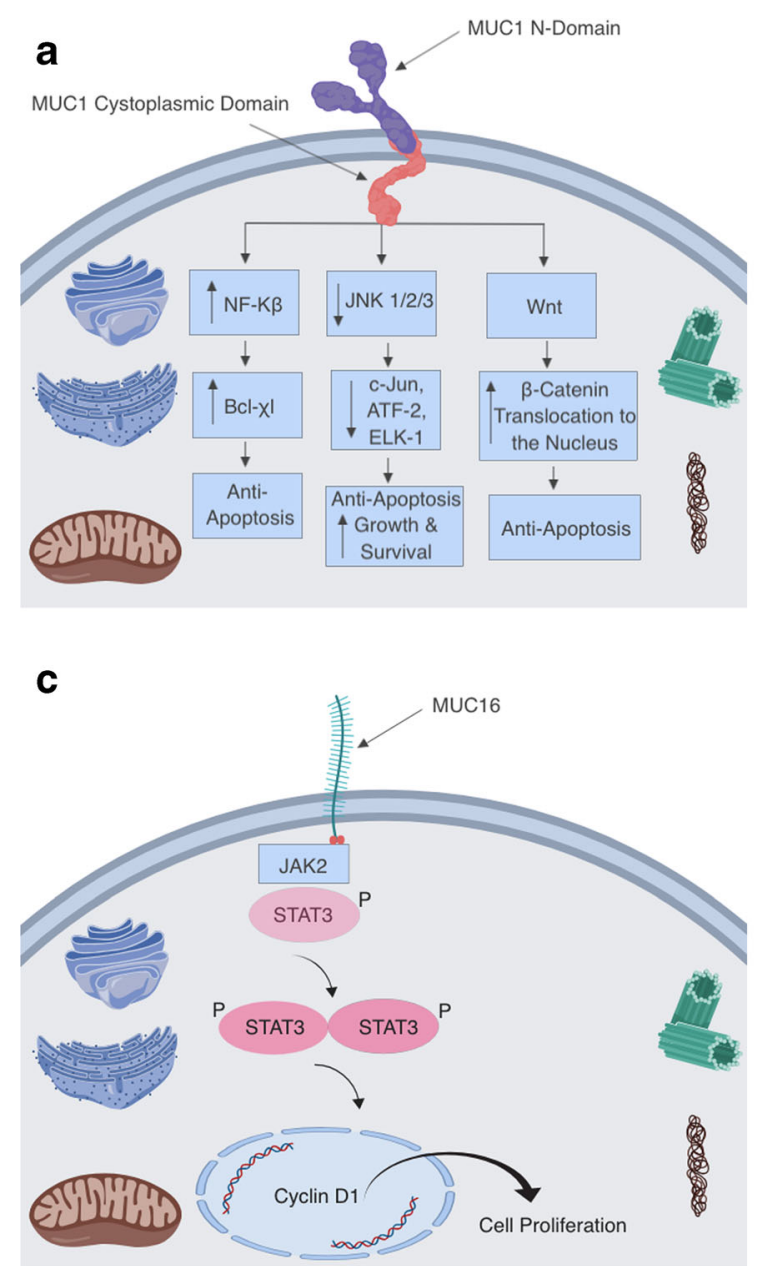

Fig. 2 Signaling pathways targeted by mucin glycoproteins. a MUC1 interacts with multiple pathways to inhibit apoptosis. b MUC4 acts as a binding partner for the HER2 receptor that ultimately promotes activating the NF- $\mathrm{BB}$ pathway and MUC1 appears to block nuclear targeting of $\mathrm{c}-\mathrm{Abl}$ in the apoptotic response to DNA damage. In summary, these studies suggest that mucin glycoproteins appear to inhibit apoptosis through different pathways that may culminate in inducing a highly apoptosis-resistant phenotype in cancer cells. Aside from involvement with multiple signaling pathways, mucin glycoprotein expression may result in excess secretion of mucin that in turn alters cell-cell and cell-matrix interactions [123], promotes metastasis [124], confers tumor cell resistance to therapeutic antibodies [125, 126], and promotes the ability of tumor cells to evade immune surveillance [127]. Mucin glycoproteins may prevent apoptosis both by altering intracellular cell signaling and by forming a physical barrier that may limit the capacity for chemotherapeutics to reach the cell.

These findings also indicate that mucin glycoproteins may represent potential therapeutic targets. Drugs that decrease the production or inhibit the actions of mucin glycoproteins may potentially reverse the resistance to chemoradiotherapy found in cancers that overexpress these proteins. Until recently, most
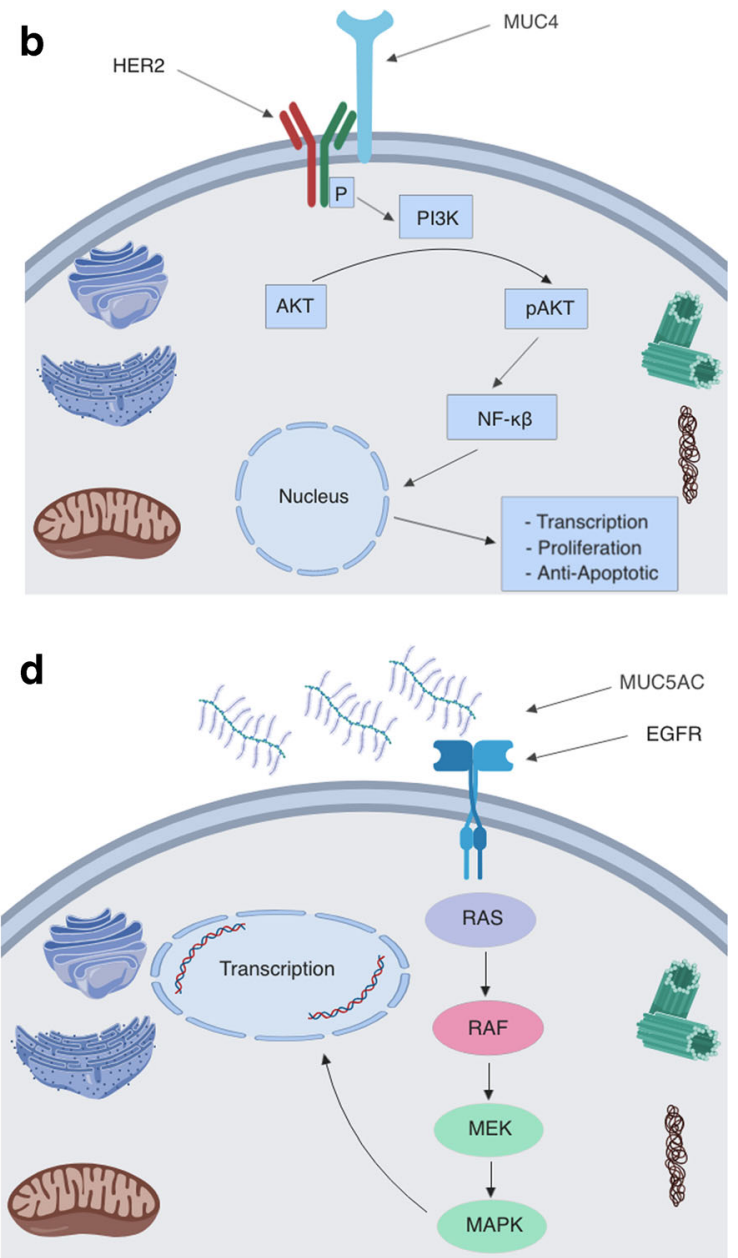

proliferation through downstream signaling. c MUC16 interacts with JAK2/STAT3 to promote proliferation. d The secretory mucins such as MUC5AC can also promote proliferation 
research on MUC1 as a target in colorectal cancer has been focused on vaccine development. These vaccines have been studied in mouse models and have been shown to cause rejection of tumor cells in the prophylactic setting and to reduce tumor burden in the therapeutic setting [128]. Vaccines against MUC1 have been tested in patients with adenomas, but data on the efficacy of these is still lacking [129]. MUC1 contains CQC residues in the cytoplasmic domain that are important for its homodimerization and function as an oncoprotein [130]. In keeping with this, direct inhibitors of MUC1-C such as GO201, GO-202, and GO-203 have been developed and work by blocking the CQC motif [131]. These inhibitors have been shown to arrest growth and induce cell death in breast cancer cells in vitro and in vivo. GO-203 has been shown to inhibit cell growth in MUC1-positive colorectal cancer cells; furthermore, it has been shown to induce regression of colon tumors in xenograft models [132]. Going forward, MUC1 inhibitors either alone or in combination with other chemotherapeutic agents may be useful in the treatment of specific subtypes of epithelial cancers. Vaccinating those with premalignant lesions against MUC1 may also become an option to prevent progression to invasive disease. Both of these potential options require more focused research efforts before their exact place, if any, in the treatment of malignancies is determined.

This systematic review identified that there has been a strong interest in MUC4, particularly in the setting of pancreatic cancer [133-135]. MUC4 is a member of the membrane-bound mucin family [136-138]. There is good evidence that implicates MUC4 in the pathogenesis of many types of cancer [33, 139-142], but particularly in the setting of pancreatic cancer $[13,124,143-151]$. Interestingly, the expression of MUC4 is undetectable in the normal pancreas $[29,152]$; however, there is a positive correlation between MUC4 expression and increasing grade of pancreatic intraepithelial neoplasia and pancreatic adenocarcinoma [153]. Silencing of MUC4 expression in pancreatic cancer cells has been shown to result in less cell proliferation and migration [101]; furthermore, reducing the expression of MUC4 has also been shown to increase sensitivity to gemcitabine [100]. MUC4 has been shown to interact with and stabilize the HER2 oncoprotein, and silencing of MUC4 has been shown to lead to the downregulation of HER2 with a concomitant decrease in its phosphorylated form [154], and it masks the antibody-binding epitope of ErbB2 leading to diminished trastuzumab binding in breast cancer [126]. MUC4 has also been shown to be a transcriptional and post-transcriptional target of K-ras oncogene in pancreatic cancer [155]. Clearly, MUC4 is a potentially attractive protein for diagnosis, prognosis, and treatment in those cancers with altered MUC4 expression [11, 12, 156-159]. Tumors that overexpress MUC4 have already been shown to have a poorer prognosis [160], and pancreatic mucin MUC4 has been shown to be able to reliably distinguish between pancreatic adenocarcinoma and pancreatitis [29]. The use of MUC4 vaccines in in vitro experiments has been reported, and these vaccines have been shown to have a potent cytotoxic response that was specific to MUC4expressing cells $[161,162]$. There is no doubt that the full diagnostic, prognostic, and therapeutic potential of MUC4 is yet to be reached.

MUC16 is another member of the membrane-bound mucin family and was found to be the third most researched mucin in this systematic review. MUC16 is an extremely large glycoprotein (22,152 amino acids) and has been used clinically as an ovarian cancer biomarker, CA125, for several decades [163-166]. MUC16 is expressed in the epithelial lining of several organs such as the ocular surface where it provides hydration and lubrication, forms a disadhesive barrier, and protects the cell surface from pathogen attack [167]. It has been shown to be overexpressed in multiple tumor types [168-171]. MUC16 has been shown to inhibit apoptosis and to increase proliferation, migration, invasion, and colony formation of pancreatic cancer cells in vitro. It has also been shown to increase tumor growth and metastasis in vivo [104, $112,115,116]$. A number of studies have examined the role of carboxyl-terminal MUC16 and have found that it can reduce TRAIL-induced apoptosis [172] and can also reduce sensitivity to cisplatin [173]. Antibodies against MUC16 such as oregovomab and abagovomab that have been used to treat patients with ovarian cancer have had limited success [174, 175]. It is believed that antibodies toward the carboxylterminal MUC16 will prove to be useful for diagnostic and therapeutic applications [163]. Preventing the cleavage of MUC16 is an alternative therapeutic strategy as it would increase the cell surface representation of MUC16 and thus enhance the efficacy of antibody-based therapeutics [176]. Targeting the interacting partners of MUC16 has also been explored with some success involving mesothelin [177]. MUC16 is another exciting potential target in the treatment of epithelial-derived malignancies.

Our findings demonstrated that mucins play a clear role in the proliferation and survival of cancer stem cells as well as in promoting resistance against chemotherapy. In addition to this, there are a number of publications highlighting the part played by mucins in the epithelial to mesenchymal transition (EMT). EMT is a reversible process associated with loss of cell polarity, decreased surface expression of epithelial markers, and increased expression of mesenchymal markers $[178,179]$. EMT plays a major part in metastatic tumor progression, drug resistance, and recurrence [180-183]. MUC1, MUC4, and MUC16 appear to play a significant role in EMT; however, the secretory mucins such as MUC5AC may also have a role in this process [184-186]. Roy et al. initially described the association between aberrant expression of MUC1 and initiation of EMT phenotype in cancer cells. They overexpressed MUC1 in pancreatic cancer cells and highlighted the direct association with EMT-related transcription factors such as SNAIL and SLUG [122]. MUC4 knockdown 
cells have been shown to have reduced expression of mesenchymal markers such as vimentin and vitronectin and increased expression of the epithelial marker cytokeratin-18, and these findings highlight the importance of MUC4 in the acquisition of the EMT phenotype [30]. There is also evidence to suggest that MUC4 can suppress EMT in lung cancer [187, 188], suggesting that MUC4 regulation of EMT is cellular dependent. Interestingly, loss of MUC16 cell surface expression induces mesenchymal features, and MUC16-deficient cells display increased invasion and motility [189]; however, other studies have demonstrated that overexpression of the cytoplasmic portion of MUC16 is associated with invasive properties [190]. Mucins appear to play a key role in EMT that is likely cellular dependent.

\section{Conclusions}

Overexpression of mucin glycoproteins, in particular MUC1, MUC4, and MUC16, appears to confer resistance to apoptosis and chemoradiotherapy as well as promoting invasion, migration, adhesion, and proliferation in many different epithelialderived cancers. Based on the findings from the studies above, it appears that mucin glycoproteins interfere with key signaling pathways. Reducing the expression of mucin glycoproteins restores the ability of cells to undergo apoptosis. More focused research into the effects of targeting the expression of mucin glycoproteins is needed to determine the possibility of using MUC inhibitors in the clinical setting.

Author contributions Study concept and design-JPB; scientific guidance-EWK and JHMP; data collection-ISR; manuscript preparation - ISR and DAM; manuscript review - all authors.

Funding information Funding for this project was received from the Beaumont Hospital Colorectal Research Trust.

\section{Compliance with ethical standards}

Conflict of interest The authors declare that they have no conflict of interest.

Publisher's Note Springer Nature remains neutral with regard to jurisdictional claims in published maps and institutional affiliations.

\section{References}

1. Krysko, O., Aaes, T. L., Kagan, V. E., D’Herde, K., Bachert, C., Leybaert, L., et al. (2017). Necroptotic cell death in anti-cancer therapy. Immunological Reviews, 280(1), 207-219.

2. Hanahan, D., \& Weinberg, R. A. (2011). Hallmarks of cancer: the next generation. Cell, 144(5), 646-674.

3. Laubenbacher, R., Hower, V., Jarrah, A., Torti, S. V., Shulaev, V., Mendes, P., et al. (2009). A systems biology view of cancer. Biochimica et Biophysica Acta, 1796(2), 129-139.
4. Eum, K. H., \& Lee, M. (2011). Crosstalk between autophagy and apoptosis in the regulation of paclitaxel-induced cell death in vHa-ras-transformed fibroblasts. Molecular and Cellular Biochemistry, 348(1-2), 61-68.

5. Kerr, J. F., Wyllie, A. H., \& Currie, A. R. (1972). Apoptosis: a basic biological phenomenon with wide-ranging implications in tissue kinetics. British Journal of Cancer, 26(4), 239-257.

6. Ghobrial, I. M., Witzig, T. E., \& Adjei, A. A. (2005). Targeting apoptosis pathways in cancer therapy. CA: a Cancer Journal for Clinicians, 55(3), 178-194.

7. Joshi, S., Kumar, S., Choudhury, A., Ponnusamy, M. P., \& Batra, S. K. (2014). Altered mucins (MUC) trafficking in benign and malignant conditions. Oncotarget, 5(17), 7272-7284.

8. Jonckheere, N., Skrypek, N., Frenois, F., \& Van Seuningen, I. (2013). Membrane-bound mucin modular domains: from structure to function. Biochimie, 95(6), 1077-1086.

9. Albrecht, H., \& Carraway, K. L., 3rd. (2011). MUC1 and MUC4: switching the emphasis from large to small. Cancer Biotherapy \& Radiopharmaceuticals., 26(3), 261-271.

10. Kufe, D. W. (2009). Mucins in cancer: function, prognosis and therapy. Nature Reviews. Cancer, 9(12), 874-885.

11. Senapati, S., Das, S., \& Batra, S. K. (2010). Mucin-interacting proteins: from function to therapeutics. Trends in Biochemical Sciences., 35(4), 236-245.

12. Rachagani, S., Torres, M. P., Moniaux, N., \& Batra, S. K. (2009). Current status of mucins in the diagnosis and therapy of cancer. BioFactors (Oxford, England)., 35(6), 509-527.

13. Kaur, S., Kumar, S., Momi, N., Sasson, A. R., \& Batra, S. K. (2013). Mucins in pancreatic cancer and its microenvironment. Nature Reviews Gastroenterology \& Hepatology., 10(10), 607-620.

14. Chaturvedi, P., Singh, A. P., \& Batra, S. K. (2008). Structure, evolution, and biology of the MUC4 mucin. FASEB Journal: official publication of the Federation of American Societies for Experimental Biology., 22(4), 966-981.

15. Tarang, S., Kumar, S., \& Batra, S. K. (2012). Mucins and toll-like receptors: kith and kin in infection and cancer. Cancer Letters., $321(2), 110-119$.

16. van der Sluis, M., Melis, M. H., Jonckheere, N., Ducourouble, M. P., Buller, H. A., Renes, I., et al. (2004). The murine Muc2 mucin gene is transcriptionally regulated by the zinc-finger GATA-4 transcription factor in intestinal cells. Biochemical and Biophysical Research Communications., 325(3), 952-960.

17. Niv, Y. (2016). Mucin gene expression in the intestine of ulcerative colitis patients: a systematic review and meta-analysis. European Journal of Gastroenterology \& Hepatology, 28(11), 1241-1245.

18. Jonckheere, N., Skrypek, N., \& Van Seuningen, I. (2014). Mucins and tumor resistance to chemotherapeutic drugs. Biochimica et Biophysica Acta, 1846(1), 142-151.

19. Moniaux, N., Andrianifahanana, M., Brand, R. E., \& Batra, S. K. (2004). Multiple roles of mucins in pancreatic cancer, a lethal and challenging malignancy. British Journal of Cancer., 91(9), 1633-1638.

20. Jonckheere, N., \& Van Seuningen, I. (2010). The membranebound mucins: from cell signalling to transcriptional regulation and expression in epithelial cancers. Biochimie, 92(1), 1-11.

21. Mukhopadhyay, P., Chakraborty, S., Ponnusamy, M. P., Lakshmanan, I., Jain, M., \& Batra, S. K. (2011). Mucins in the pathogenesis of breast cancer: implications in diagnosis, prognosis and therapy. Biochimica et Biophysica Acta, 1815(2), 224 240.

22. Lakshmanan, I., Ponnusamy, M. P., Macha, M. A., Haridas, D., Majhi, P. D., Kaur, S., et al. (2015). Mucins in lung cancer: diagnostic, prognostic, and therapeutic implications. Journal of 
Thoracic Oncology: official publication of the International Association for the Study of Lung Cancer., 10(1), 19-27.

23. Krishn, S. R., Kaur, S., Smith, L. M., Johansson, S. L., Jain, M., Patel, A., et al. (2016). Mucins and associated glycan signatures in colon adenoma-carcinoma sequence: prospective pathological implication(s) for early diagnosis of colon cancer. Cancer letters., 374(2), 304-314.

24. Pai, P., Rachagani, S., Dhawan, P., \& Batra, S. K. (2016). Mucins and Wnt/beta-catenin signaling in gastrointestinal cancers: an unholy nexus. Carcinogenesis, 37(3), 223-232.

25. Kumar, S., Das, S., Rachagani, S., Kaur, S., Joshi, S., Johansson, S. L., et al. (2015). NCOA3-mediated upregulation of mucin expression via transcriptional and post-translational changes during the development of pancreatic cancer. Oncogene, 34(37), 48794889.

26. Perrais, M., Rousseaux, C., Ducourouble, M. P., Courcol, R., Vincent, P., Jonckheere, N., et al. (2014). Helicobacter pylori urease and flagellin alter mucin gene expression in human gastric cancer cells. Gastric Cancer : official journal of the International Gastric Cancer Association and the Japanese Gastric Cancer Association., 17(2), 235-246.

27. Shibahara, H., Higashi, M., Yokoyama, S., Rousseau, K., Kitazono, I., Osako, M., et al. (2014). A comprehensive expression analysis of mucins in appendiceal carcinoma in a multicenter study: MUC3 is a novel prognostic factor. PLoS One, 9(12), e115613.

28. Jonckheere, N., \& Van Seuningen, I. (2008). The membranebound mucins: how large O-glycoproteins play key roles in epithelial cancers and hold promise as biological tools for gene-based and immunotherapies. Critical Reviews in Oncogenesis., 14(2-3), 177-196.

29. Andrianifahanana, M., Moniaux, N., Schmied, B. M., Ringel, J., Friess, H., Hollingsworth, M. A., et al. (2001). Mucin (MUC) gene expression in human pancreatic adenocarcinoma and chronic pancreatitis: a potential role of MUC4 as a tumor marker of diagnostic significance. Clinical Cancer Research : an official journal of the American Association for Cancer Research, 7(12), 40334040.

30. Mukhopadhyay, P., Lakshmanan, I., Ponnusamy, M. P., Chakraborty, S., Jain, M., Pai, P., et al. (2013). MUC4 overexpression augments cell migration and metastasis through EGFR family proteins in triple negative breast cancer cells. PLoS One, 8(2), e54455.

31. Senapati, S., Chaturvedi, P., Sharma, P., Venkatraman, G., Meza, J. L., El-Rifai, W., et al. (2008). Deregulation of MUC4 in gastric adenocarcinoma: potential pathobiological implication in poorly differentiated non-signet ring cell type gastric cancer. British Journal of Cancer, 99(6), 949-956.

32. Singh, A. P., Chauhan, S. C., Bafna, S., Johansson, S. L., Smith, L. M., Moniaux, N., et al. (2006). Aberrant expression of transmembrane mucins, MUC1 and MUC4, in human prostate carcinomas. The Prostate, 66(4), 421-429.

33. Kaur, S., Momi, N., Chakraborty, S., Wagner, D. G., Horn, A. J., Lele, S. M., et al. (2014). Altered expression of transmembrane mucins, MUC1 and MUC4, in bladder cancer: pathological implications in diagnosis. PLoS One, 9(3), e92742.

34. Moher, D., Shamseer, L., Clarke, M., Ghersi, D., Liberati, A., Petticrew, M., et al. (2015). Preferred reporting items for systematic review and meta-analysis protocols (PRISMA-P) 2015 statement. Systematic Reviews, 4, 1.

35. Dilly, A. K., Honick, B. D., Lee, Y. J., Guo, Z. S., Zeh, H. J., Bartlett, D. L., et al. (2017). Targeting G-protein coupled receptor-related signaling pathway in a murine xenograft model of appendiceal pseudomyxoma peritonei. Oncotarget, 8(63), 106888-106900.
36. Garcia, E. P., Tiscornia, I., Libisch, G., Trajtenberg, F., BollatiFogolin, M., Rodriguez, E., et al. (2016). MUC5B silencing reduces chemo-resistance of MCF-7 breast tumor cells and impairs maturation of dendritic cells. International Journal of Oncology, 48(5), 2113-2123.

37. Lakshmanan, I., Ponnusamy, M. P., Das, S., Chakraborty, S., Haridas, D., Mukhopadhyay, P., et al. (2012). MUC16 induced rapid G2/M transition via interactions with JAK2 for increased proliferation and anti-apoptosis in breast cancer cells. Oncogene, 31(7), 805-817.

38. Workman, H. C., Sweeney, C., \& Carraway, K. L., 3rd. (2009). The membrane mucin Muc4 inhibits apoptosis induced by multiple insults via ErbB2-dependent and ErbB2-independent mechanisms. Cancer Research, 69(7), 2845-2852.

39. Hattrup, C. L., \& Gendler, S. J. (2006). MUC1 alters oncogenic events and transcription in human breast cancer cells. Breast Cancer Research, 8(4), R37.

40. Schroeder, J. A., Masri, A. A., Adriance, M. C., Tessier, J. C., Kotlarczyk, K. L., Thompson, M. C., et al. (2004). MUC1 overexpression results in mammary gland tumorigenesis and prolonged alveolar differentiation. Oncogene, 23(34), 5739-5747.

41. Li, Y., Pang, Z., Dong, X., Liao, X., Deng, H., Liao, C., et al. (2018). MUC1 induces M2 type macrophage influx during postpartum mammary gland involution and triggers breast cancer. Oncotarget, 9(3), 3446-3458.

42. Jin, W., Liao, X., Lv, Y., Pang, Z., Wang, Y., Li, Q., et al. (2017). MUC1 induces acquired chemoresistance by upregulating ABCB1 in EGFR-dependent manner. Cell Death \& Disease, $8(8)$, e2980.

43. Zhu, X., Long, X., Luo, X., Song, Z., Li, S., \& Wang, H. (2016). Abrogation of MUC5AC expression contributes to the apoptosis and cell cycle arrest of colon cancer cells. Cancer Biotherapy \& Radiopharmaceuticals, 31(7), 261-267.

44. Sheng, Y. H., He, Y., Hasnain, S. Z., Wang, R., Tong, H., Clarke, D. T., et al. (2017). MUC13 protects colorectal cancer cells from death by activating the NF-kappaB pathway and is a potential therapeutic target. Oncogene, 36(5), 700-713.

45. Chen, Q., Li, D., Ren, J., Li, C., \& Xiao, Z. X. (2013). MUC1 activates JNK1 and inhibits apoptosis under genotoxic stress. Biochemical and Biophysical Research Communications, 440(1), 179-183.

46. Ren, J., Agata, N., Chen, D., Li, Y., Yu, W. H., Huang, L., et al. (2004). Human MUC1 carcinoma-associated protein confers resistance to genotoxic anticancer agents. Cancer Cell, 5(2), 163175.

47. Costa, N. R., Paulo, P., Caffrey, T., Hollingsworth, M. A., \& Santos-Silva, F. (2011). Impact of MUC1 mucin downregulation in the phenotypic characteristics of MKN45 gastric carcinoma cell line. PLoS One, 6(11), e26970.

48. Yi, F. T., \& Lu, Q. P. (2017). Mucin 1 promotes radioresistance in hepatocellular carcinoma cells through activation of JAK2/STAT3 signaling. Oncology Letters, 14(6), 7571-7576.

49. Yuan, H., Wang, J., Wang, F., Zhang, N., Li, Q., Xie, F., et al. (2015). Mucin 1 gene silencing inhibits the growth of SMMC7721 human hepatoma cells through Bax-mediated mitochondrial and caspase-8-mediated death receptor apoptotic pathways. Molecular Medicine Reports, 12(5), 6782-6788.

50. Li, Q., Wang, F., Liu, G., Yuan, H., Chen, T., Wang, J., et al. (2014). Impact of Mucin1 knockdown on the phenotypic characteristics of the human hepatocellular carcinoma cell line SMMC7721. Oncology Reports, 31(6), 2811-2819.

51. Xu, T., Li, D., Wang, H., Zheng, T., Wang, G., \& Xin, Y. (2017). MUC1 downregulation inhibits non-small cell lung cancer progression in human cell lines. Experimental and Therapeutic Medicine, 14(5), 4443-4447. 
52. Xu, X., Wells, A., Padilla, M. T., Kato, K., Kim, K. C., \& Lin, Y. (2014). A signaling pathway consisting of miR-551b, catalase and MUC1 contributes to acquired apoptosis resistance and chemoresistance. Carcinogenesis, 35(11), 2457-2466.

53. Gao, J., McConnell, M. J., Yu, B., Li, J., Balko, J. M., Black, E. P., et al. (2009). MUC1 is a downstream target of STAT3 and regulates lung cancer cell survival and invasion. International Journal of Oncology, 35(2), 337-345.

54. Grover, P., Nath, S., Nye, M. D., Zhou, R., Ahmad, M., \& Mukherjee, P. (2018). SMAD4-independent activation of TGFbeta signaling by MUC1 in a human pancreatic cancer cell line. Oncotarget, 9(6), 6897-6910.

55. Zhao, P., Meng, M., Xu, B., Dong, A., Ni, G., \& Lu, L. (2017). Decreased expression of MUC1 induces apoptosis and inhibits migration in pancreatic cancer PANC-1 cells via regulation of Slug pathway. Cancer Biomarkers, 20(4), 469-476.

56. Trehoux, S., Duchene, B., Jonckheere, N., \& Van Seuningen, I. (2015). The MUC1 oncomucin regulates pancreatic cancer cell biological properties and chemoresistance. Implication of p42-44 MAPK, Akt, Bcl-2 and MMP13 pathways. Biochemical and Biophysical Research Communications, 456(3), 757-762.

57. Jonckheere, N., Skrypek, N., Merlin, J., Dessein, A. F., Dumont, P., Leteurtre, E., et al. (2012). The mucin MUC4 and its membrane partner ErbB2 regulate biological properties of human CAPAN-2 pancreatic cancer cells via different signalling pathways. PLoS One, 7(2), e32232.

58. Bafna, S., Kaur, S., Momi, N., \& Batra, S. K. (2009). Pancreatic cancer cells resistance to gemcitabine: the role of MUC4 mucin. British Journal of Cancer, 101(7), 1155-1161.

59. Chaturvedi, P., Singh, A. P., Moniaux, N., Senapati, S., Chakraborty, S., Meza, J. L., et al. (2007). MUC4 mucin potentiates pancreatic tumor cell proliferation, survival, and invasive properties and interferes with its interaction to extracellular matrix proteins. Molecular Cancer Research: MCR, 5(4), 309-320.

60. Hoshi, H., Sawada, T., Uchida, M., Iijima, H., Kimura, K., Hirakawa, K., et al. (2013). MUC5AC protects pancreatic cancer cells from TRAIL-induced death pathways. International Journal of Oncology, 42(3), 887-893.

61. Sheng, Y., Ng, C. P., Lourie, R., Shah, E. T., He, Y., Wong, K. Y., et al. (2017). MUC13 overexpression in renal cell carcinoma plays a central role in tumor progression and drug resistance. International Journal of Cancer, 140(10), 2351-2363.

62. Zhao, Q., Piyush, T., Chen, C., Hollingsworth, M. A., Hilkens, J., Rhodes, J. M., et al. (2014). MUC1 extracellular domain confers resistance of epithelial cancer cells to anoikis. Cell Death \& Disease, e1438, 5.

63. Yin, L., Li, Y., Ren, J., Kuwahara, H., \& Kufe, D. (2003). Human MUC1 carcinoma antigen regulates intracellular oxidant levels and the apoptotic response to oxidative stress. The Journal of Biological Chemistry, 278(37), 35458-35464.

64. Raina, D., Ahmad, R., Kumar, S., Ren, J., Yoshida, K., Kharbanda, S., et al. (2006). MUC1 oncoprotein blocks nuclear targeting of $\mathrm{c}-\mathrm{Abl}$ in the apoptotic response to DNA damage. The EMBO Journal, 25(16), 3774-3783.

65. Rowson-Hodel, A. R., Wald, J. H., Hatakeyama, J., O’Neal, W. K., Stonebraker, J. R., VanderVorst, K., et al. (2018). Membrane mucin Muc4 promotes blood cell association with tumor cells and mediates efficient metastasis in a mouse model of breast cancer. Oncogene, 37(2), 197-207.

66. Astashchanka, A., Shroka, T. M., \& Jacobsen, B. M. (2018). Mucin 2 (MUC2) modulates the aggressiveness of breast cancer. Breast Cancer Research and Treatment.

67. Reinartz, S., Failer, S., Schuell, T., \& Wagner, U. (2012). CA125 (MUC16) gene silencing suppresses growth properties of ovarian and breast cancer cells. European Journal of Cancer (Oxford, England: 1990), 48(10), 1558-1569.
68. Liu, Q., Cheng, Z., Luo, L., Yang, Y., Zhang, Z., Ma, H., et al. (2016). C-terminus of MUC16 activates Wnt signaling pathway through its interaction with beta-catenin to promote tumorigenesis and metastasis. Oncotarget, 7(24), 36800-36813.

69. Valque, H., Gouyer, V., Gottrand, F., \& Desseyn, J. L. (2012). MUC5B leads to aggressive behavior of breast cancer MCF7 cells. PLoS One, 7(10), e46699.

70. Fessler, S. P., Wotkowicz, M. T., Mahanta, S. K., \& Bamdad, C. (2009). MUC1* is a determinant of trastuzumab (Herceptin) resistance in breast cancer cells. Breast Cancer Research and Treatment, 118(1), 113-124.

71. Chen, A. C., Migliaccio, I., Rimawi, M., Lopez-Tarruella, S., Creighton, C. J., Massarweh, S., et al. (2012). Upregulation of mucin4 in ER-positive/HER2-overexpressing breast cancer xenografts with acquired resistance to endocrine and HER2targeted therapies. Breast Cancer Research and Treatment, 134(2), 583-593.

72. Maeda, T., Hiraki, M., Jin, C., Rajabi, H., Tagde, A., Alam, M., et al. (2018). MUC1-C induces PD-L1 and immune evasion in triple-negative breast cancer. Cancer Research., 78(1), 205-215.

73. Alam, M., Rajabi, H., Ahmad, R., Jin, C., \& Kufe, D. (2014). Targeting the MUC1-C oncoprotein inhibits self-renewal capacity of breast cancer cells. Oncotarget, 5(9), 2622-2634.

74. Kharbanda, A., Rajabi, H., Jin, C., Raina, D., \& Kufe, D. (2013). Oncogenic MUC1-C promotes tamoxifen resistance in human breast cancer. Molecular Cancer Research: MCR, 11(7), 714-723.

75. Raina, D., Uchida, Y., Kharbanda, A., Rajabi, H., Panchamoorthy, G., Jin, C., et al. (2014). Targeting the MUC1-C oncoprotein downregulates HER2 activation and abrogates trastuzumab resistance in breast cancer cells. Oncogene, 33(26), 3422-3431.

76. Uchida, Y., Raina, D., Kharbanda, S., \& Kufe, D. (2013). Inhibition of the MUC1-C oncoprotein is synergistic with cytotoxic agents in the treatment of breast cancer cells. Cancer Biology \& Therapy, 14(2), 127-134.

77. Das, S., Rachagani, S., Sheinin, Y., Smith, L. M., Gurumurthy, C. B., Roy, H. K., et al. (2016). Mice deficient in Muc4 are resistant to experimental colitis and colitis-associated colorectal cancer. Oncogene, 35(20), 2645-2654.

78. Gupta, B. K., Maher, D. M., Ebeling, M. C., Stephenson, P. D., Puumala, S. E., Koch, M. R., et al. (2014). Functions and regulation of MUC13 mucin in colon cancer cells. Journal of Gastroenterology, 49(10), 1378-1391.

79. Bruyere, E., Jonckheere, N., Frenois, F., Mariette, C., \& Van Seuningen, I. (2011). The MUC4 membrane-bound mucin regulates esophageal cancer cell proliferation and migration properties: Implication for S100A4 protein. Biochemical and Biophysical Research Communications, 413(2), 325-329.

80. Gronnier, C., Bruyere, E., Lahdaoui, F., Jonckheere, N., Perrais, M., Leteurtre, E., et al. (2014). The MUC1 mucin regulates the tumorigenic properties of human esophageal adenocarcinomatous cells. Biochimica et Biophysica Acta, 1843(11), 2432-2437.

81. Lahdaoui, F., Messager, M., Vincent, A., Hec, F., Gandon, A., Warlaumont, M., et al. (2017). Depletion of MUC5B mucin in gastrointestinal cancer cells alters their tumorigenic properties: implication of the Wnt/beta-catenin pathway. The Biochemical Journal, 474(22), 3733-3746.

82. Deng, M., Jing, D. D., \& Meng, X. J. (2013). Effect of MUC1 siRNA on drug resistance of gastric cancer cells to trastuzumab. Asian Pacific Journal of Cancer Prevention: APJCP, 14(1), 127-131.

83. Shi, M., Yang, Z., Hu, M., Liu, D., Hu, Y., Qian, L., et al. (2013). Catecholamine-induced beta2-adrenergic receptor activation mediates desensitization of gastric cancer cells to trastuzumab by upregulating MUC4 expression. Journal of Immunology (Baltimore, Md: 1950), 190(11), 5600-5608. 
84. Macha, M. A., Rachagani, S., Pai, P., Gupta, S., Lydiatt, W. M., Smith, R. B., et al. (2015). MUC4 regulates cellular senescence in head and neck squamous cell carcinoma through $\mathrm{p} 16 / \mathrm{Rb}$ pathway. Oncogene, 34(13), 1698-1708.

85. Lakshmanan, I., Salfity, S., Seshacharyulu, P., Rachagani, S., Thomas, A., Das, S., et al. (2017). MUC16 regulates TSPYL5 for lung cancer cell growth and chemoresistance by suppressing p53. Clinical Cancer Research, 23(14), 3906-3917.

86. Lakshmanan, I., Rachagani, S., Hauke, R., Krishn, S. R., Paknikar, S., Seshacharyulu, P., et al. (2016). MUC5AC interactions with integrin beta4 enhances the migration of lung cancer cells through FAK signaling. Oncogene, 35(31), 4112-4121.

87. Majhi, P. D., Lakshmanan, I., Ponnusamy, M. P., Jain, M., Das, S., Kaur, S., et al. (2013). Pathobiological implications of MUC4 in non-small-cell lung cancer. Journal of Thoracic Oncology: official publication of the International Association for the Study of Lung Cancer, 8(4), 398-407.

88. Kanwal, M., Ding, X. J., Song, X., Zhou, G. B., \& Cao, Y. (2018). MUC16 overexpression induced by gene mutations promotes lung cancer cell growth and invasion. Oncotarget, 9(15), 12226 12239.

89. Raina, D., Kosugi, M., Ahmad, R., Panchamoorthy, G., Rajabi, H., Alam, M., et al. (2011). Dependence on the MUC1-C oncoprotein in non-small cell lung cancer cells. Molecular Cancer Therapeutics, 10(5), 806-816.

90. Bouillez, A., Gnemmi, V., Gaudelot, K., Hemon, B., Ringot, B., Pottier, N., et al. (2014). MUC1-C nuclear localization drives invasiveness of renal cancer cells through a sheddase/gamma secretase dependent pathway. Oncotarget, 5(3), 754-763.

91. Aubert, S., Fauquette, V., Hemon, B., Lepoivre, R., Briez, N., Bernard, D., et al. (2009). MUC1, a new hypoxia inducible factor target gene, is an actor in clear renal cell carcinoma tumor progression. Cancer Research, 69(14), 5707-5715.

92. Alam, M., Ahmad, R., Rajabi, H., Kharbanda, A., \& Kufe, D. (2013). MUC1-C oncoprotein activates ERK $\rightarrow$ C/EBPbeta signaling and induction of aldehyde dehydrogenase $1 \mathrm{~A} 1$ in breast cancer cells. The Journal of Biological Chemistry, 288(43), 3089230903.

93. Mimeault, M., Johansson, S. L., Senapati, S., Momi, N., Chakraborty, S., \& Batra, S. K. (2010). MUC4 down-regulation reverses chemoresistance of pancreatic cancer stem/progenitor cells and their progenies. Cancer Letters, 295(1), 69-84.

94. Huang, W. C., Chan, M. L., Chen, M. J., Tsai, T. H., \& Chen, Y. J. (2016). Modulation of macrophage polarization and lung cancer cell stemness by MUC1 and development of a related smallmolecule inhibitor pterostilbene. Oncotarget, 7(26), 3936339375.

95. Wang, R., Yang, L., Li, S., Ye, D., Yang, L., Liu, Q., et al. (2018). Quercetin inhibits breast cancer stem cells via downregulation of aldehyde dehydrogenase 1A1 (ALDH1A1), chemokine receptor type 4 (CXCR4), mucin 1 (MUC1), and epithelial cell adhesion molecule (EpCAM). Medical Science Monitor: international medical journal of experimental and clinical research, 24, 412420.

96. Hiraki, M., Maeda, T., Bouillez, A., Alam, M., Tagde, A., Hinohara, K., et al. (2017). MUC1-C activates BMI1 in human cancer cells. Oncogene, 36(20), 2791-2801.

97. Zhou, N., Zhang, Y., Zhang, X., Lei, Z., Hu, R., Li, H., et al. (2015). Exposure of tumor-associated macrophages to apoptotic MCF-7 cells promotes breast cancer growth and metastasis. International Journal of Molecular Sciences, 16(6), 1196611982.

98. Engelmann, K., Shen, H., \& Finn, O. J. (2008). MCF7 side population cells with characteristics of cancer stem/progenitor cells express the tumor antigen MUC1. Cancer research, 68(7), 2419-2426.
99. Das, S., Rachagani, S., Torres-Gonzalez, M. P., Lakshmanan, I., Majhi, P. D., Smith, L. M., et al. (2015). Carboxyl-terminal domain of MUC16 imparts tumorigenic and metastatic functions through nuclear translocation of JAK2 to pancreatic cancer cells. Oncotarget, 6(8), 5772-5787.

100. Skrypek, N., Duchene, B., Hebbar, M., Leteurtre, E., van Seuningen, I., \& Jonckheere, N. (2013). The MUC4 mucin mediates gemcitabine resistance of human pancreatic cancer cells via the Concentrative Nucleoside Transporter family. Oncogene, 32(13), 1714-1723.

101. Lahdaoui, F., Delpu, Y., Vincent, A., Renaud, F., Messager, M., Duchene, B., et al. (2015). miR-219-1-3p is a negative regulator of the mucin MUC4 expression and is a tumor suppressor in pancreatic cancer. Oncogene, 34(6), 780-788.

102. Trehoux, S., Lahdaoui, F., Delpu, Y., Renaud, F., Leteurtre, E., Torrisani, J., et al. (2015). Micro-RNAs miR-29a and miR-330$5 \mathrm{p}$ function as tumor suppressors by targeting the MUC1 mucin in pancreatic cancer cells. Biochimica et Biophysica Acta, $1853(10 \mathrm{Pt}$ A), 2392-2403.

103. Jahan, R., Macha, M. A., Rachagani, S., Das, S., Smith, L. M., Kaur, S., et al. (2018). Axed MUC4 (MUC4/X) aggravates pancreatic malignant phenotype by activating integrin-beta1/FAK/ ERK pathway. Biochimica et Biophysica Acta - Molecular Basis of Disease, 1864(8), 2538-2549.

104. Muniyan, S., Haridas, D., Chugh, S., Rachagani, S., Lakshmanan, I., Gupta, S., et al. (2016). MUC16 contributes to the metastasis of pancreatic ductal adenocarcinoma through focal adhesion mediated signaling mechanism. Genes \& Cancer, 7(3-4), 110-124.

105. Seshacharyulu, P., Ponnusamy, M. P., Rachagani, S., Lakshmanan, I., Haridas, D., Yan, Y., et al. (2015). Targeting EGF-receptor(s) - STAT1 axis attenuates tumor growth and metastasis through downregulation of MUC4 mucin in human pancreatic cancer. Oncotarget, 6(7), 5164-5181.

106. Lakshmanan, I., Seshacharyulu, P., Haridas, D., Rachagani, S., Gupta, S., Joshi, S., et al. (2015). Novel HER3/MUC4 oncogenic signaling aggravates the tumorigenic phenotypes of pancreatic cancer cells. Oncotarget, 6(25), 21085-21099.

107. Pai, P., Rachagani, S., Lakshmanan, I., Macha, M. A., Sheinin, Y., Smith, L. M., et al. (2016). The canonical Wnt pathway regulates the metastasis-promoting mucin MUC4 in pancreatic ductal adenocarcinoma. Molecular Oncology, 10(2), 224-239.

108. Rachagani, S., Macha, M. A., Ponnusamy, M. P., Haridas, D., Kaur, S., Jain, M., et al. (2012). MUC4 potentiates invasion and metastasis of pancreatic cancer cells through stabilization of fibroblast growth factor receptor 1. Carcinogenesis, 33(10), 19531964.

109. Momi, N., Ponnusamy, M. P., Kaur, S., Rachagani, S., Kunigal, S. S., Chellappan, S., et al. (2013). Nicotine/cigarette smoke promotes metastasis of pancreatic cancer through alpha $7 \mathrm{nAChR}$ mediated MUC4 upregulation. Oncogene, 32(11), 1384-1395.

110. Moniaux, N., Chaturvedi, P., Varshney, G. C., Meza, J. L., Rodriguez-Sierra, J. F., Aubert, J. P., et al. (2007). Human MUC4 mucin induces ultra-structural changes and tumorigenicity in pancreatic cancer cells. British Journal of Cancer, 97(3), 345357.

111. Senapati, S., Gnanapragassam, V. S., Moniaux, N., Momi, N., \& Batra, S. K. (2012). Role of MUC4-NIDO domain in the MUC4mediated metastasis of pancreatic cancer cells. Oncogene, 31(28), 3346-3356.

112. Shukla, S. K., Gunda, V., Abrego, J., Haridas, D., Mishra, A., Souchek, J., et al. (2015). MUC16-mediated activation of mTOR and c-Myc reprograms pancreatic cancer metabolism. Oncotarget, 6(22), 19118-19131.

113. Singh, A. P., Moniaux, N., Chauhan, S. C., Meza, J. L., \& Batra, S. K. (2004). Inhibition of MUC4 expression suppresses pancreatic 
tumor cell growth and metastasis. Cancer Research, 64(2), 622630 .

114. Torres, M. P., Ponnusamy, M. P., Chakraborty, S., Smith, L. M., Das, S., Arafat, H. A., et al. (2010). Effects of thymoquinone in the expression of mucin 4 in pancreatic cancer cells: implications for the development of novel cancer therapies. Molecular Cancer Therapeutics, 9(5), 1419-1431.

115. Shimizu, A., Hirono, S., Tani, M., Kawai, M., Okada, K., Miyazawa, M., et al. (2012). Coexpression of MUC16 and mesothelin is related to the invasion process in pancreatic ductal adenocarcinoma. Cancer Science, 103(4), 739-746.

116. Lee, J., Lee, J., Yun, J. H., Jeong, D. G., \& Kim, J. H. (2016). DUSP28 links regulation of mucin 5B and mucin 16 to migration and survival of AsPC-1 human pancreatic cancer cells. Tumour Biology: the journal of the International Society for Oncodevelopmental Biology and Medicine, 37(9), 12193-12202.

117. Hoshi, H., Sawada, T., Uchida, M., Saito, H., Iijima, H., TodaAgetsuma, M., et al. (2011). Tumor-associated MUC5AC stimulates in vivo tumorigenicity of human pancreatic cancer. International Journal of Oncology, 38(3), 619-627.

118. Yamazoe, S., Tanaka, H., Sawada, T., Amano, R., Yamada, N., Ohira, M., et al. (2010). RNA interference suppression of mucin 5AC (MUC5AC) reduces the adhesive and invasive capacity of human pancreatic cancer cells. Journal of Experimental \& Clinical Cancer Research: CR, 29, 53.

119. Chauhan, S. C., Ebeling, M. C., Maher, D. M., Koch, M. D., Watanabe, A., Aburatani, H., et al. (2012). MUC13 mucin augments pancreatic tumorigenesis. Molecular Cancer Therapeutics, 11(1), 24-33.

120. Wissniowski, T. T., Meister, S., Hahn, E. G., Kalden, J. R., Voll, R., \& Ocker, M. (2012). Mucin production determines sensitivity to bortezomib and gemcitabine in pancreatic cancer cells. International Journal of Oncology., 40(5), 1581-1589.

121. Nath, S., Daneshvar, K., Roy, L. D., Grover, P., Kidiyoor, A., Mosley, L., et al. (2013). MUC1 induces drug resistance in pancreatic cancer cells via upregulation of multidrug resistance genes. Oncogene, e51, 2.

122. Roy, L. D., Sahraei, M., Subramani, D. B., Besmer, D., Nath, S., Tinder, T. L., et al. (2011). MUC1 enhances invasiveness of pancreatic cancer cells by inducing epithelial to mesenchymal transition. Oncogene, 30(12), 1449-1459.

123. Komatsu, M., Carraway, C. A., Fregien, N. L., \& Carraway, K. L. (1997). Reversible disruption of cell-matrix and cell-cell interactions by overexpression of sialomucin complex. The Journal of Biological Chemistry, 272(52), 33245-33254.

124. Komatsu, M., Tatum, L., Altman, N. H., Carothers Carraway, C. A., \& Carraway, K. L. (2000). Potentiation of metastasis by cell surface sialomucin complex (rat MUC4), a multifunctional antiadhesive glycoprotein. International Journal of Cancer, 87(4), 480-486.

125. Price-Schiavi, S. A., Jepson, S., Li, P., Arango, M., Rudland, P. S., Yee, L., et al. (2002). Rat Muc4 (sialomucin complex) reduces binding of anti-ErbB2 antibodies to tumor cell surfaces, a potential mechanism for herceptin resistance. International Journal of Cancer, 99(6), 783-791.

126. Nagy, P., Friedlander, E., Tanner, M., Kapanen, A. I., Carraway, K. L., Isola, J., et al. (2005). Decreased accessibility and lack of activation of ErbB2 in JIMT-1, a herceptin-resistant, MUC4-expressing breast cancer cell line. Cancer Research, 65(2), 473-482.

127. Komatsu, M., Yee, L., \& Carraway, K. L. (1999). Overexpression of sialomucin complex, a rat homologue of MUC4, inhibits tumor killing by lymphokine-activated killer cells. Cancer Research, 59(9), 2229-2236.

128. Mukherjee, P., Pathangey, L. B., Bradley, J. B., Tinder, T. L., Basu, G. D., Akporiaye, E. T., et al. (2007). MUC1-specific immune therapy generates a strong anti-tumor response in a MUC1tolerant colon cancer model. Vaccine, 25(9), 1607-1618.

129. Kimura, T., McKolanis, J. R., Dzubinski, L. A., Islam, K., Potter, D. M., Salazar, A. M., et al. (2013). MUC1 vaccine for individuals with advanced adenoma of the colon: a cancer immunoprevention feasibility study. Cancer Prevention Research (Philadelphia, Pa.), 6(1), 18-26.

130. Leng, Y., Cao, C., Ren, J., Huang, L., Chen, D., Ito, M., et al. (2007). Nuclear import of the MUC1-C oncoprotein is mediated by nucleoporin Nup62. The Journal of Biological Chemistry, 282(27), 19321-19330.

131. Raina, D., Ahmad, R., Joshi, M. D., Yin, L., Wu, Z., Kawano, T., et al. (2009). Direct targeting of the mucin 1 oncoprotein blocks survival and tumorigenicity of human breast carcinoma cells. Cancer Research, 69(12), 5133-5141.

132. Ahmad, R., Alam, M., Hasegawa, M., Uchida, Y., Al-Obaid, O., Kharbanda, S., et al. (2017). Targeting MUC1-C inhibits the AKTS6K1-elF4A pathway regulating TIGAR translation in colorectal cancer. Molecular Cancer, 16(1), 33.

133. Choudhury, A., Singh, R. K., Moniaux, N., El-Metwally, T. H., Aubert, J. P., \& Batra, S. K. (2000). Retinoic acid-dependent transforming growth factor-beta 2-mediated induction of MUC4 mucin expression in human pancreatic tumor cells follows retinoic acid receptor-alpha signaling pathway. The Journal of Biological Chemistry, 275(43), 33929-33936.

134. Jain, M., Venkatraman, G., Moniaux, N., Kaur, S., Kumar, S., Chakraborty, S., et al. (2011). Monoclonal antibodies recognizing the non-tandem repeat regions of the human mucin MUC4 in pancreatic cancer. PLoS One, 6(8), e23344.

135. Gautam, S. K., Kumar, S., Cannon, A., Hall, B., Bhatia, R., Nasser, M. W., et al. (2017). MUC4 mucin - a therapeutic target for pancreatic ductal adenocarcinoma. Expert Opinion on Therapeutic Targets, 21(7), 657-669.

136. Moniaux, N., Nollet, S., Porchet, N., Degand, P., Laine, A., \& Aubert, J. P. (1999). Complete sequence of the human mucin MUC4: a putative cell membrane-associated mucin. The Biochemical Journal, 338(Pt 2), 325-333.

137. Nollet, S., Moniaux, N., Maury, J., Petitprez, D., Degand, P., Laine, A., et al. (1998). Human mucin gene MUC4: organization of its $5^{\prime}$-region and polymorphism of its central tandem repeat array. The Biochemical Journal, 332(Pt 3), 739-748.

138. Bafna, S., Singh, A. P., Moniaux, N., Eudy, J. D., Meza, J. L., \& Batra, S. K. (2008). MUC4, a multifunctional transmembrane glycoprotein, induces oncogenic transformation of NIH3T3 mouse fibroblast cells. Cancer Research, 68(22), 9231-9238.

139. Ponnusamy, M. P., Lakshmanan, I., Jain, M., Das, S., Chakraborty, S., Dey, P., et al. (2010). MUC4 mucin-induced epithelial to mesenchymal transition: a novel mechanism for metastasis of human ovarian cancer cells. Oncogene, 29(42), 5741-5754.

140. Piessen, G., Jonckheere, N., Vincent, A., Hemon, B., Ducourouble, M. P., Copin, M. C., et al. (2007). Regulation of the human mucin MUC4 by taurodeoxycholic and taurochenodeoxycholic bile acids in oesophageal cancer cells is mediated by hepatocyte nuclear factor 1alpha. The Biochemical Journal, 402(1), 81-91.

141. Mariette, C., Perrais, M., Leteurtre, E., Jonckheere, N., Hemon, B., Pigny, P., et al. (2004). Transcriptional regulation of human mucin MUC4 by bile acids in oesophageal cancer cells is promoterdependent and involves activation of the phosphatidylinositol 3kinase signalling pathway. The Biochemical Journal, 377(Pt 3), 701-708.

142. Pai, P., Rachagani, S., Dhawan, P., Sheinin, Y. M., Macha, M. A., Qazi, A. K., et al. (2016). MUC4 is negatively regulated through the Wnt/beta-catenin pathway via the Notch effector Hath1 in colorectal cancer. Genes \& Cancer, 7(5-6), 154-168. 
143. Komatsu, M., Jepson, S., Arango, M. E., Carothers Carraway, C. A., \& Carraway, K. L. (2001). Muc4/sialomucin complex, an intramembrane modulator of ErbB2/HER2/Neu, potentiates primary tumor growth and suppresses apoptosis in a xenotransplanted tumor. Oncogene, 20(4), 461-470.

144. Jonckheere, N., Skrypek, N., \& Van Seuningen, I. (2010). Mucins and pancreatic cancer. Cancers, 2(4), 1794-1812.

145. Jonckheere, N., Perrais, M., Mariette, C., Batra, S. K., Aubert, J. P., Pigny, P., et al. (2004). A role for human MUC4 mucin gene, the ErbB2 ligand, as a target of TGF-beta in pancreatic carcinogenesis. Oncogene, 23(34), 5729-5738.

146. Fauquette, V., Perrais, M., Cerulis, S., Jonckheere, N., Ducourouble, M. P., Aubert, J. P., et al. (2005). The antagonistic regulation of human MUC4 and ErbB-2 genes by the Ets protein PEA3 in pancreatic cancer cells: implications for the proliferation/ differentiation balance in the cells. The Biochemical Journal, 386(Pt 1), 35-45.

147. Kaur, S., Sharma, N., Krishn, S. R., Lakshmanan, I., Rachagani, S., Baine, M. J., et al. (2014). MUC4-mediated regulation of acute phase protein lipocalin 2 through HER2/AKT/NF-kappaB signaling in pancreatic cancer. Clinical Cancer Research: an official journal of the American Association for Cancer Research, 20(3), 688-700.

148. Singh, A. P., Chauhan, S. C., Andrianifahanana, M., Moniaux, N., Meza, J. L., Copin, M. C., et al. (2007). MUC4 expression is regulated by cystic fibrosis transmembrane conductance regulator in pancreatic adenocarcinoma cells via transcriptional and posttranslational mechanisms. Oncogene, 26(1), 30-41.

149. Choudhury, A., Moniaux, N., Ulrich, A. B., Schmied, B. M., Standop, J., Pour, P. M., et al. (2004). MUC4 mucin expression in human pancreatic tumours is affected by organ environment: the possible role of TGFbeta2. British Journal of Cancer, 90(3), 657-664.

150. Joshi, S., Cruz, E., Rachagani, S., Guha, S., Brand, R. E., Ponnusamy, M. P., et al. (2016). Bile acids-mediated overexpression of MUC4 via FAK-dependent c-Jun activation in pancreatic cancer. Molecular Oncology, 10(7), 1063-1077.

151. Andrianifahanana, M., Singh, A. P., Nemos, C., Ponnusamy, M. P., Moniaux, N., Mehta, P. P., et al. (2007). IFN-gamma-induced expression of MUC4 in pancreatic cancer cells is mediated by STAT-1 upregulation: a novel mechanism for IFN-gamma response. Oncogene, 26(51), 7251-7261.

152. Iacobuzio-Donahue, C. A., Ashfaq, R., Maitra, A., Adsay, N. V., Shen-Ong, G. L., Berg, K., et al. (2003). Highly expressed genes in pancreatic ductal adenocarcinomas: a comprehensive characterization and comparison of the transcription profiles obtained from three major technologies. Cancer Research, 63(24), 8614-8622.

153. Swartz, M. J., Batra, S. K., Varshney, G. C., Hollingsworth, M. A., Yeo, C. J., Cameron, J. L., et al. (2002). MUC4 expression increases progressively in pancreatic intraepithelial neoplasia. American Journal of Clinical Pathology, 117(5), 791-796.

154. Chaturvedi, P., Singh, A. P., Chakraborty, S., Chauhan, S. C., Bafna, S., Meza, J. L., et al. (2008). MUC4 mucin interacts with and stabilizes the HER2 oncoprotein in human pancreatic cancer cells. Cancer Research, 68(7), 2065-2070.

155. Vasseur, R., Skrypek, N., Duchene, B., Renaud, F., MartinezMaqueda, D., Vincent, A., et al. (2015). The mucin MUC4 is a transcriptional and post-transcriptional target of K-ras oncogene in pancreatic cancer. Implication of MAPK/AP-1, NF-kappaB and RalB signaling pathways. Biochimica et Biophysica Acta, 1849(12), 1375-1384.

156. Rachagani, S., Torres, M. P., Kumar, S., Haridas, D., Baine, M., Macha, M. A., et al. (2012). Mucin (Muc) expression during pancreatic cancer progression in spontaneous mouse model: potential implications for diagnosis and therapy. Journal of Hematology \& Oncology, 5, 68.
157. Singh, A. P., Chaturvedi, P., \& Batra, S. K. (2007). Emerging roles of MUC4 in cancer: a novel target for diagnosis and therapy. Cancer Research, 67(2), 433-436.

158. Torres, M. P., Chakraborty, S., Souchek, J., \& Batra, S. K. (2012). Mucin-based targeted pancreatic cancer therapy. Current Pharmaceutical Design, 18(17), 2472-2481.

159. Carraway, K. L., Theodoropoulos, G., Kozloski, G. A., \& Carothers Carraway, C. A. (2009). Muc4/MUC4 functions and regulation in cancer. Future Oncology (London, England), 5(10), 1631-1640.

160. Jonckheere, N., \& Van Seuningen, I. (2018). Integrative analysis of the cancer genome atlas and cancer cell lines encyclopedia large-scale genomic databases: MUC4/MUC16/MUC20 signature is associated with poor survival in human carcinomas. Journal of Translational Medicine, 16(1), 259.

161. Wei, J., Gao, W., Wu, J., Meng, K., Zhang, J., Chen, J., et al. (2008). Dendritic cells expressing a combined PADRE/MUC4derived polyepitope DNA vaccine induce multiple cytotoxic Tcell responses. Cancer Biotherapy \& Radiopharmaceuticals, 23(1), 121-128.

162. Wu, J., Wei, J., Meng, K., Chen, J., Gao, W., Zhang, J., et al. (2009). Identification of an HLA-A*0201-restrictive CTL epitope from MUC4 for applicable vaccine therapy. Immunopharmacology and Immunotoxicology, 31(3), 468-476.

163. Das, S., \& Batra, S. K. (2015). Understanding the unique attributes of MUC16 (CA125): potential implications in targeted therapy. Cancer Research, 75(22), 4669-4674.

164. O’Brien, T. J., Beard, J. B., Underwood, L. J., Dennis, R. A., Santin, A. D., \& York, L. (2001). The CA 125 gene: an extracellular superstructure dominated by repeat sequences. Tumour Biology: the journal of the International Society for Oncodevelopmental Biology and Medicine, 22(6), 348-366.

165. O’Brien, T. J., Beard, J. B., Underwood, L. J., \& Shigemasa, K. (2002). The CA 125 gene: a newly discovered extension of the glycosylated N-terminal domain doubles the size of this extracellular superstructure. Tumour Biology: the journal of the International Society for Oncodevelopmental Biology and Medicine, 23(3), 154-169.

166. Yin, B. W., Dnistrian, A., \& Lloyd, K. O. (2002). Ovarian cancer antigen CA125 is encoded by the MUC16 mucin gene. International Journal of Cancer, 98(5), 737-740.

167. Haridas, D., Ponnusamy, M. P., Chugh, S., Lakshmanan, I., Seshacharyulu, P., \& Batra, S. K. (2014). MUC16: molecular analysis and its functional implications in benign and malignant conditions. FASEB Journal: official publication of the Federation of American Societies for Experimental Biology, 28(10), 4183-4199.

168. Streppel, M. M., Vincent, A., Mukherjee, R., Campbell, N. R., Chen, S. H., Konstantopoulos, K., et al. (2012). Mucin 16 (cancer antigen 125) expression in human tissues and cell lines and correlation with clinical outcome in adenocarcinomas of the pancreas, esophagus, stomach, and colon. Human Pathology, 43(10), 1755-1763.

169. Aithal, A., Rauth, S., Kshirsagar, P., Shah, A., Lakshmanan, I., Junker, W. M., et al. (2018). MUC16 as a novel target for cancer therapy. Expert Opinion on Therapeutic Targets, 22(8), 675-686.

170. Haridas, D., Chakraborty, S., Ponnusamy, M. P., Lakshmanan, I., Rachagani, S., Cruz, E., et al. (2011). Pathobiological implications of MUC16 expression in pancreatic cancer. PLoS One, 6(10), e26839.

171. Bafna, S., Kaur, S., \& Batra, S. K. (2010). Membrane-bound mucins: the mechanistic basis for alterations in the growth and survival of cancer cells. Oncogene, 29(20), 2893-2904.

172. Matte, I., Lane, D., Boivin, M., Rancourt, C., \& Piche, A. (2014). MUC16 mucin (CA125) attenuates TRAIL-induced apoptosis by 
decreasing TRAIL receptor R2 expression and increasing c-FLIP expression. BMC Cancer, 14, 234.

173. Boivin, M., Lane, D., Piche, A., \& Rancourt, C. (2009). CA125 (MUC16) tumor antigen selectively modulates the sensitivity of ovarian cancer cells to genotoxic drug-induced apoptosis. Gynecologic Oncology, 115(3), 407-413.

174. Berek, J. S., Taylor, P. T., Gordon, A., Cunningham, M. J., Finkler, N., Orr, J., Jr., et al. (2004). Randomized, placebo-controlled study of oregovomab for consolidation of clinical remission in patients with advanced ovarian cancer. Journal of Clinical Oncology: official journal of the American Society of Clinical Oncology, 22(17), 3507-3516.

175. Sabbatini, P., Harter, P., Scambia, G., Sehouli, J., Meier, W., Wimberger, P., et al. (2013). Abagovomab as maintenance therapy in patients with epithelial ovarian cancer: a phase III trial of the AGO OVAR, COGI, GINECO, and GEICO - the MIMOSA study. Journal of Clinical Oncology : official journal of the American Society of Clinical Oncology, 31(12), 1554-1561.

176. Das, S., Majhi, P. D., Al-Mugotir, M. H., Rachagani, S., Sorgen, P., \& Batra, S. K. (2015). Membrane proximal ectodomain cleavage of MUC16 occurs in the acidifying Golgi/post-Golgi compartments. Scientific Reports, 5, 9759.

177. Garg, G., Gibbs, J., Belt, B., Powell, M. A., Mutch, D. G., Goedegebuure, P., et al. (2014). Novel treatment option for MUC16-positive malignancies with the targeted TRAIL-based fusion protein Meso-TR3. BMC Cancer, 14, 35.

178. Thiery, J. P., \& Sleeman, J. P. (2006). Complex networks orchestrate epithelial-mesenchymal transitions. Nature Reviews. Molecular Cell Biology, 7(2), 131-142.

179. Thiery, J. P., Acloque, H., Huang, R. Y., \& Nieto, M. A. (2009). Epithelial-mesenchymal transitions in development and disease. Cell, 139(5), 871-890.

180. Ahmed, N., Abubaker, K., Findlay, J., \& Quinn, M. (2010). Epithelial mesenchymal transition and cancer stem cell-like phenotypes facilitate chemoresistance in recurrent ovarian cancer. Current Cancer Drug Targets, 10(3), 268-278.

181. Lim, S., Becker, A., Zimmer, A., Lu, J., Buettner, R., \& Kirfel, J. (2013). SNAI1-mediated epithelial-mesenchymal transition confers chemoresistance and cellular plasticity by regulating genes involved in cell death and stem cell maintenance. PLoS One, $8(6)$, e66558.
182. Voulgari, A., \& Pintzas, A. (2009). Epithelial-mesenchymal transition in cancer metastasis: mechanisms, markers and strategies to overcome drug resistance in the clinic. Biochimica et Biophysica Acta, 1796(2), 75-90.

183. Yamada, S., Fuchs, B. C., Fujii, T., Shimoyama, Y., Sugimoto, H., Nomoto, S., et al. (2013). Epithelial-to-mesenchymal transition predicts prognosis of pancreatic cancer. Surgery, 154(5), 946-954.

184. Ponnusamy, M. P., Seshacharyulu, P., Lakshmanan, I., Vaz, A. P., Chugh, S., \& Batra, S. K. (2013). Emerging role of mucins in epithelial to mesenchymal transition. Current Cancer Drug Targets, 13(9), 945-956.

185. Rajabi, H., Alam, M., Takahashi, H., Kharbanda, A., Guha, M., Ahmad, R., et al. (2014). MUC1-C oncoprotein activates the ZEB1/miR-200c regulatory loop and epithelial-mesenchymal transition. Oncogene, 33(13), 1680-1689.

186. Gnemmi, V., Bouillez, A., Gaudelot, K., Hemon, B., Ringot, B., Pottier, N., et al. (2014). MUC1 drives epithelial-mesenchymal transition in renal carcinoma through Wnt/beta-catenin pathway and interaction with SNAIL promoter. Cancer Letters, 346(2), 225-236.

187. Gao, L., Liu, J., Zhang, B., Zhang, H., Wang, D., Zhang, T., et al. (2014). Functional MUC4 suppress epithelial-mesenchymal transition in lung adenocarcinoma metastasis. Tumour Biology: the journal of the International Society for Oncodevelopmental Biology and Medicine, 35(2), 1335-1341.

188. Jonckheere, N., \& Van Seuningen, I. (2014). Comment on: Functional MUC4 suppress epithelial-mesenchymal transition in lung adenocarcinoma metastasis. Gao L, Liu J, Zhang B, Zhang H, Wang D, Zhang T, Liu Y, Wang C. Tumour Biol. 2013, in press. Tumour Biology: the journal of the International Society for Oncodevelopmental Biology and Medicine, 35(4), 3941-3942.

189. Comamala, M., Pinard, M., Theriault, C., Matte, I., Albert, A., Boivin, M., et al. (2011). Downregulation of cell surface CA125/ MUC16 induces epithelial-to-mesenchymal transition and restores EGFR signalling in NIH:OVCAR3 ovarian carcinoma cells. British Journal of Cancer, 104(6), 989-999.

190. Theriault, C., Pinard, M., Comamala, M., Migneault, M., Beaudin, J., Matte, I., et al. (2011). MUC16 (CA125) regulates epithelial ovarian cancer cell growth, tumorigenesis and metastasis. Gynecologic Oncology, 121(3), 434-443. 